\title{
Prospective earthquake forecasts at the Himalayan front after the 25 April $2015 M=7.8$ Gorkha mainshock
}

\author{
Accepted for publication
}

Seismological Research Letters

\author{
Margarita Segou ${ }^{1}$ and Tom Parsons ${ }^{2}$ \\ 1. British Geological Survey, Edinburgh, UK 2. U.S. Geological Survey, Menlo Park, California
}

When a major earthquake strikes, the resulting devastation can be compounded or even exceeded by the subsequent cascade of triggered seismicity. As the Nepalese recover from the 25 April 2015 shock, knowledge of what comes next is essential. We calculate the redistribution of crustal stresses and implied earthquake probabilities for different periods from daily to 30 years into the future. An initial forecast was completed before a $M=7.3$ earthquake struck on May 12, 2015 that enables a preliminary assessment; post-forecast seismicity has so far occurred within a zone of 5-fold probability gain. Evaluation of the forecast performance, using 2 months of seismic data, reveals that stress-based approaches present improved skill in higher magnitude triggered seismicity. Our results suggest that considering the total stress field, rather than only the co-seismic one, improves the spatial performance of the model based on the estimation of a wide range of potential triggered faults following a mainshock. 


\section{Introduction}

The Himalayas rise by absorbing 18-22 $\mathrm{mm} / \mathrm{yr}$ of Indian-Eurasian plate convergence (Ader $e t$ al., 2012) (Fig. 1). On the $25^{\text {th }}$ of April, 2015, a $M=7.8$ earthquake ruptured the low-angle $\left(10^{\circ}\right)$ fault contact between the two plates, leading to more than 8000 confirmed fatalities, 18,000 people injured, and a million families affected (Nepal Red Cross Society ${ }^{1}$ ). Eight UNESCO World Heritage sites were damaged or destroyed. The 25 April shock struck the eastern edge of a 500-km-wide gap between historic earthquakes along the Himalayan front (Fig. 1). The potential of triggered earthquakes beneath highly populated basins in the central Himalaya could compound this catastrophe akin to tragedies in Turkey (Parsons et al., 2000), China (Parsons et al., 2008), and New Zealand (Stramondo et al., 2011). Recent studies, based on retrospective experiments, investigate the predictive power of short-term earthquake forecasts within different distance ranges and periods (Segou et al., 2013; Strader and Jackson, 2015), but prospective forecasts still face challenges such as the quality of real-time data, the availability of credible historical/modern earthquake catalogs , and very short research windows.

In this study, we calculate the expected redistribution of stress in the Himalayan crust and develop a method, especially applicable to frontier regions, to determine the probability of triggered earthquakes in both space and time. We make prospective earthquake forecasts using four methods incorporating physics-based and statistical approaches for varying time horizons, and formally evaluate the shortest-term calculations.

The results reveal the efficiency of physics-based forecasts in estimating short-term earthquake probabilities and their critical contribution in modeling off-fault triggered events, highlighted by the $M=5.6$ Xegar ( 3 hours after the mainshock) and the $M=7.3$ Kodari (May 12) earthquakes.

\section{Development of Short-Term Earthquake Forecasts}

Short-term earthquake forecasts can use empirical statistics to anticipate cascades of triggered events, or simulations of stress redistribution following a mainshock combined with conceptual friction models to describe triggered earthquake occurrence (Harris, 1998; Stein, 1999). Neither method flawlessly accounts for the spectrum of post mainshock earthquake behavior (e.g., Nanjo et al., 2012; Cocco et al., 2010; Segou et al., 2014). Empirical/statistical models depend heavily on the density of the local seismic network and identification of precursory activity and are thus vulnerable in frontier regions. In this study, we employ an Epidemic Type Aftershock Sequence (ETAS) model as a benchmark to compare the efficiency of our physics-based forecasts in capturing all possible triggering mechanisms (Ogata, 1988; Ogata, 1998; see ETAS implementation section, available in the electronic supplement to this article).

\footnotetext{
${ }^{1}$ Available information at http://www.nrcs.org
} 
Physics-based models depend on accurate simulation of a mainshock rupture and its transfer of stress onto neighboring active crustal faults. In this context Coulomb failure stress is described by the equation

$$
\Delta C F=\Delta\left|\overline{\tau_{f}}\right|+\mu^{\prime}\left(\Delta \sigma_{n}\right)
$$

where $\Delta\left|\bar{\tau}_{f}\right|$ is the change in shear stress on the receiver fault, $\Delta \sigma_{n}$ is the change in normal stress, $\mu^{\prime}=\mu\left(1-B_{k}\right)$ is the effective coefficient of friction, and $B_{k}$ is Skempton's coefficient that accounts for pore fluid pressure effects. Stress values are found by slipping an elastic dislocation representation of the mainshock slip model provided by USGS in near-real time, and calculating Coulomb failure stress changes on hypothetical faults optimally oriented to the regional stress field (King et al., 1994; Harris, 1998), wherein faults may be brought closer to, or further from failure. The friction coefficient is taken to be $\mu=0.4$ in all cases for uniform comparision. A 10 $\mathrm{MPa}$ deviatoric tectonic stress with compression oriented $\mathrm{N} 19^{\circ} \mathrm{E}$ (Jouanne et al., 2004; Bollinger et al., 2004) is used to find optimally oriented receiver fault planes. Additionally, we calculate stress changse on planes parallel to, and on the mainshock fault to find likely future rupture areas on the main boundary fault and other possibly hidden faults of like orientation (Wobus et al., 2005). All maps of stress change in the manuscript are shown at $10 \mathrm{~km}$ depth, which is where the majority of aftershocks were located during the first 5 days after the mainshock.

In order to convert calculated stress changes to forecast earthquake rates, we follow the rate-andstate friction framework (Dieterich, 1994; Dieterich, 1996) where the pre-mainshock earthquake activity $r$ and the time-dependent seismicity rate $R$ we aim to predict are connected through the equation, $R=\frac{r}{\gamma \dot{\tau}}$,

where $\gamma_{n}=\gamma_{n-1} \exp \left(\frac{-\Delta C F}{\alpha \sigma}\right)$

The decay rate of the stress effect $\Delta \mathrm{CF}$ is inversely correlated with the shear-stressing rate $(\dot{\tau})$ as taken from the relation $t_{\alpha}=\frac{\alpha \sigma}{\dot{\tau}}$, where $t_{\alpha}$ is the aftershock duration, and $\alpha \sigma$ is a fault constitutive parameter (see Conversion of stress changes to forecast earthquake rates section, available in the electronic supplement to this article).

A persistent problem with physical models is that triggered earthquakes often happen in areas of calculated stress reduction known as stress shadows (Harris and Simpson, 1996), where theoretically they should be suppressed (Mallman and Zoback, 2007; Parsons et al., 2012). We thus develop an approach to address the issue of calculated stress decreases that we call the total stress method. The total stress calculation reports the complete (preseismic and coseismic) stress field rather than just coseismic changes because aftershocks may be responding to the regional stress field on non-optimal planes in areas where there are calculated coseismic stress decreases. In this mode there are no expected regions of earthquake suppression because there is always a possible fault orientation that is favorable for failure. Therefore certain earthquake mechanisms may be suppressed, but others are encouraged (Mallman and Parsons, 2008; Hardebeck, 2014).

The total stress method differs from standard stress change methods, but shares the following traits: the total stress tensor is the sum of the pre-mainshock stress (based on N19 ${ }^{\circ}$ E-directed 10 MPa-deviatoric stress) and stress-change tensors 


$$
\sigma_{x, y, z}^{T}=\sigma_{x, y, z}^{P R E}+\Delta \sigma_{x, y, z}
$$

The post-mainshock principal stress axes are the diagonal components of the tensor rotated such that the shear components are zero. Following Jaeger and Cook (1976), the strike angle between principal stress axes and the theoretical maximum stress-change fault plane $\beta$ is from $\tan (2 \beta)=$ $1 / \mu$. At this point, methods in general use (King et al., 1994; Toda et al., 2005; Toda and Enescu, 2011) calculate stress changes that are determined only by the earthquake stress changes on these planes, which can be positive or negative. The total stress method differs because in an earthquake prone region with strong differential stress, it is almost always possible to find a fault orientation where Coulomb failure is favored. An example highlighting the importance of the total stress methods for Northern California is available to the electronic supplement of this paper. (Fig. S1). To find these failure planes, a grid search is performed in $5^{\circ}$ steps over dip and rake to maximize Coulomb failure for all possible mechanism classes (reverse, normal, and transform).

As destructive as the 2015 Gorkha earthquake was, interpretation of paleoseismological (Rajendran et al., 2015; Bollinger et al., 2014; Sakopta et al., 2013) and historical shaking intensity observations shows that earthquakes well above $\mathrm{M}=8$ occur routinely along the Himalayan front (Bilham et al., 2001) (Fig. 1). Therefore, in order to gain some sense of the impact of the 25 April $M=7.8$ mainshock on future earthquakes along the Main Himalayan thrust, we also make time-dependent probability calculations (e.g. Parsons et al., 2010; Console et al., 2010). We estimate time dependent probability using a Brownian Passage Time (BPT) distribution with aperiodicity $=0.5$ and bracket the calculations with mean recurrence intervals ranging from 750-870 years and last earthquake times either 1255 or 1505 (Rajendran et al., 2015; Bollinger et al., 2014; Sakopta et al., 2013). Hardebeck (2004) discusses about the importance of the assumptions in using BPT distribution together within rate-and-state framework, while Parsons (2005) notes the significance behind using stress changes in estimating time-dependent probabilities when the latter are considerably greater than the calculated tectonic stressing rate.

\section{RESULTS}

We find that traditional stress change calculations resolved on faults parallel to the mainshock and onto optimal faults cannot fully explain the first 5 days of triggered earthquakes after the 25 April mainshock. The total stress method greatly increases the array of possible failure planes, and more closely represents complex tectonic environments like Nepal, which has thrust, strike-slip, and normal faults in close proximity (Yeats et al., 1992). This exercise does not produce stress shadows since the total stress is always positive. We find only $12 \%$ of events (Fig. 2c) triggered by the 25 April 2015 Nepal mainshock happening in areas where the maximum total stress is less than the pre-seismic levels, which would be conceptually similar to a stress shadow. By contrast, standard methods have $48 \%-72 \%$ of triggered events (Fig. 2a-b) happening in areas with calculated stress reduction. We note that all methods show the Katmandu basin under a co-seismic stress increase.

We estimate an average stress increase of $0.15 \mathrm{MPa}$ for the Thankot fault $\left(M_{\max } \sim 6.6\right)$, located at the southwest edge of the Katmandu basin. To the southwest, calculations show stress increased by $0.32 \mathrm{MPa}$ on the Kulekhani fault $\left(M_{\max } \sim 6.9\right)$ (NSET report, 2010). Stress was increased by $0.28 \mathrm{MPa}$ on the Kalphu-Khola fault $\left(M_{\max } \sim 6.9\right)$ north of Katmandu. Nepal's 
second largest city, Pokhara, lies to the west of the 25 April rupture and had a smaller coseismic stress increase $(0.05 \mathrm{MPa})$ than in the Katmandu basin. Aggregated probability from mapped faults in the Katmandu Basin shows a $90 \%$ chance of at least one more $M \geq 4.7$ shock in the next 5 years.

We calculate up to $0.1 \mathrm{MPa}$ coseismic stress increase on the deep decollement beneath the Himalayas (Fig 2d), and a $0.65 \mathrm{MPa}$ increase on the main boundary thrust immediately west of the 2015 mainshock rupture.

We estimate the spatio-temporal distribution of triggered earthquakes above the magnitude completeness level of $\mathrm{M} \geq 4.7$ within daily time intervals. The total-stress forecast predicted higher (relative to other methods) earthquake rates along an extended part the Himalayan front, including triggered seismicity in rift basins that cut across the Himalayas (Fig. 3d). We find evidence for widespread triggered seismicity during the initial hours, as demonstrated by the $M=5.7$ Xegar event $245 \mathrm{~km}$ east of the mainshock.

Our benchmark ETAS model shows signs of under-forecasting (Fig. 3a) because epidemictype forecasts (earthquake cascades) rely on smaller magnitude events that tend to be unreported in Nepal. Statistical models perform best when local earthquake networks are capable of providing the highest quality data (Helmstetter, 2003). The two initial 5-day forecasts we produced based on standard physics (Fig. 3b-c) also underforecast the early triggered earthquake rates and were spatially limited, failing to capture the breadth of the triggered earthquake region.

A $M=7.3$ earthquake struck Nepal at Kodari on 12 May 2015, 17 days after, and $157 \mathrm{~km}$ away from the 25 April $2015 M=7.8$ mainshock. This second large earthquake inflicted further casualties and damage to a region already impacted by the initial shock, and exemplifies the purpose of making post-mainshock earthquake forecasts. Our prospective earthquake forecast was submitted to the American Association for the Advancement of Science (AAAS) on 9 May 2015 (available in the electronic supplement to this article), 56 hours before the $M=7.3$ event occurred; this timing enables us to assess forecast performance prospectively.

The $M=7.3$ Kodari event struck within a zone where we calculated elevated probability, with $27 \%$ odds of a $M \geq 4.7$ in 5 years (9-fold probability gain over the pre-mainshock value of $\sim 3 \%$ ) (Fig. 4). All regional $M \geq 4.7$ seismicity between 25 April and 10 August 2015 has occurred within a zone of 5 -fold probability gain over background. We calculated a $0.05 \mathrm{MPa}$ stress increase at the future hypocenter of the $M=7.3$ shock, and that the most likely rupture would strike $327^{\circ}$, dip $34^{\circ}$, and have a $135^{\circ}$ rake. Observed rupture parameters ${ }^{2}$ are: strike $=303^{\circ}$, dip $=9^{\circ}$, and rake $=110^{\circ}$. Uncertainties in determining these values from seismograms are typically $\pm 20^{\circ}$ (Kagan, 2003). We therefore conclude that the 12 May $2015 M=7.3$ event was triggered by the $M=7.8$ mainshock.

Following the standards set by the International Commission on Earthquake Forecasting in the aftermath of the catastrophic 2009 L'Aquila earthquake in Italy, an earthquake forecast has to

\footnotetext{
${ }^{2}$ Rupture mechanism for the greater triggered event is available at: http://earthquake.usgs.gov/earthquakes/eventpage/us20002ejl\#scientific tensor
} 
exhibit reliability and skill. The forecast models are updated to incorporate the stress effects of the $M=7.3$ Kodari triggered event, and the available earthquake information for 2 months following the mainshock. We employ a performance evaluation using statistical metrics suggested through the framework of the Collaboratory of the Study of Earthquake Predictability (CSEP) in recent literature (Jordan et al., 2011; Rhoades et al., 2011; Schorlemmer et al., 2007; Zechar et al., 2010; Woessner et al., 2011).

The tested models are updated to incorporate the stress effects of the $M=7.3$ triggered event. Furthermore, we provide a map-view comparison between the initial and updated forecasts based on the total-stress method plotted with the observed seismicity (Fig. 5). The $M=7.3$ event raises the expected number in almost all active parts of the study grid, yet most activity so far is concentrated near the $\mathrm{M}>7$ shocks.

We implement the modified $N$-, $S$-, and $T$-tests to evaluate the absolute (Fig. 6) and relative (Fig. 7) performance of the updated forecast models within 10 day windows after the $M=7.8$ Nepal mainshock. Within these windows, 36, 21, 3, 1, 2, and $1 M \geq 4.7$ earthquake(s) occurred, characterizing a low-productivity sequence. The tests focus on the first 20 days (0-10, 10-20 days time intervals) following the mainshock because there are not enough events over the period from 20-60 days to make meaningful calculations. We note that the benchmark ETAS model uses all available triggered events within the aforementioned time intervals.

The results suggest that: (1) the statistical, standard physics-based, and total stress forecast models are do not pass the test due to underestimation and overestimation of the observed seismicity, reflected by the corresponding small $\delta_{1}$ and $\delta_{2}$ values, respectively. (2) The mean loglikelihood per spatial bin in triggered earthquake locations for the period immediately following the mainshock reveals that the total stress method achieves better spatial performance $\left(\mathrm{LL}_{\mathrm{s}}{ }^{\text {Total }}=-\right.$ 1.12), followed by physics-based optimal, parallel faults, and then the statistical model $\left(\mathrm{LL}_{\mathrm{s}}{ }^{\text {Optimal }}=-3.22, \mathrm{LL}_{\mathrm{s}}{ }^{\text {Parallel }}=-5.96, \mathrm{LL}_{\mathrm{s}}{ }^{\mathrm{ETAS}}=-8.78\right)$. (3) Physics-based models outperform the standard physics-based and statistical models in locations of $M>6$ triggered events following the mainshock as expressed by the sum of log-likelihood during each time period (0-10, 10-20 days). In that context we note that $\mathrm{jLL}_{\mathrm{s}}{ }^{\text {Total }}=-6.0874, \mathrm{LL}_{\mathrm{s}}{ }^{\text {Optimal }}=-18.4026, \mathrm{LL}_{\mathrm{s}}{ }^{\text {Parallel }}=-28.4325, \mathrm{LL}_{\mathrm{s}}{ }^{\text {ETAS }}=-$ 55.4833 and $j L_{\mathrm{s}}{ }^{\text {Total }}=-1.8580, \mathrm{LL}_{\mathrm{s}}{ }^{\text {Parallel }}=-9.1080, \mathrm{LL}_{\mathrm{s}}{ }^{\text {Optimal }}=-9.1643, \mathrm{LL}_{\mathrm{s}}{ }^{\mathrm{ETAS}}=-35.6646$, for time periods 0-10 and 10-20 days, respectively. The spatial distribution of log-likelihoods within our study grid is presented in Fig. 7 for the aforementioned time intervals and, (4) The relative performance of the forecasts exhibits large spatial variability within physics-based models, but they also yield information gain over the benchmark ETAS model between $G=0.75-1.25$ (Fig. S2, available in the electronic supplement to this article).

Further evaluation of our updated prospective forecast including all available catalog data for the first 6 months following the mainshock shows that the benchmark statistical model ETAS together with the standard physics-based approaches present low rejection ratios $\left(R_{\mathrm{ETAS}}=\right.$ $R_{\text {Parallel }}=R_{\text {Optimal }} \sim 1 \%$ ) for the daily $N$ test (Fig. S3). However, they are rejected due to underestimation of observed seismicity at the 2 most critical time intervals immediately following the mainshock and the largest triggered event of the sequence. On the other hand the total stress method has comparable performance $\left(R_{\text {Total }}=8 \%\right)$ with the upside of passing the $N$ test the first day after the mainshock. 
Lastly, our 30-year time dependent probability calculation on the stress-increased areas of the main boundary thrust west of the 25 April $2015 M=7.8$ mainshock, show that values have been increased from the pre-Gorkha level $5-8 \%$, up to as much as $29 \%$. In Fig. 4 we present the aforementioned time dependent probability considering the average, maximum co-seismic stress changes and alternative recurrence parameters.

\section{Conclusions}

Formal testing of the prospective forecast using 60 days of triggered earthquake occurrence shows strong performance of physics-based methods in anticipating the highest magnitude events $(M>6)$. All methods struggled with capturing the cumulative number of triggered earthquakes, either underestimating or overestimating during the first 20 days. Spatial performance evaluations are difficult in low productivity sequences because slowly stressed regions can take years to produce enough earthquakes for the predictability of these models to be fully assessed.

Statistical methods rely heavily on precursory activity to identify future larger earthquake locations; the $M=7.3$ Kodari shock was not preceded by detectable seismicity, meaning that event was only forecasted by physics-based methods. The calibration of statistical forecasts using the near-real time available earthquake catalog was a great challenge but also gave us the opportunity to prospectively test the efficiency of empirical cascading models under poor detection thresholds. We do not regard our findings as evidence of ETAS failure; instead they are more an illustration under which conditions statistical models can reach their best performance.

However, standard physics-based approaches and the total stress method also forecast higher probability in areas that have so far not experienced large aftershocks, and therefore score low against some formal testing metrics. More time and more earthquakes will enable a more complete evaluation. Although no single event should be used to validate a prospective forecast, we are of course most interested in the expected occurrence of the largest magnitude triggered events. In that context, the $M=7.3$ Kodari and $M=5.6$ Xegar earthquake exemplified the contribution of stress-based approaches in identifying possible nucleation sites even in the absence of precursor seismicity.

These tradeoffs lead us to conclude that forecasts should rely on hybrid models that combine physical and statistical models in time and space.

\section{Data and resources}

In this study we have used the finite source models for the mainshock and the largest aftershock as well as seismic parameters for this earthquake sequence available at the USGS web-site [http://earthquake.usgs.gov, last accessed August 2015].

\section{Acknowledgements}

We thank Eric Geist and Ruth Harris for their helpful comments, two anonymous reviewers, the Associate Editor Sue Hough and the Editor of SRL Zhigang Peng for their suggestions regarding the presentation of the manuscript. 


\section{References}

Ader, T., Avouac, J.P., Liu-Zeng J., Lyon-Caen H., Bollinger, L. et al., (2012). Convergence rate across the Nepal Himalaya and interseismic coupling on the Main Himalayan Thrust: implications for seismic hazard, J. Geophys. Res. 117, B04403

Bollinger L., Sapkota, S.N., Tapponier, P., Klinger, Y. Rizza, M. et al. (2014)Estimating the return times of great Himalayan earthquakes in eastern Nepal: evidence from the Patu and Bardibas strand of the Main Frontal Thrust, J. Geophys. Res. 119, 7123-7163.

Bilham, R., Gaur, V. K., Molnar, P. (2001). Himalayan seismic hazard, Science 293, 1442-1444.

Bakun, W. H. \& Wentworth, C. M. (1997) Estimating earthquake location and magnitude from seismic intensity data, Bull. Seismol. Soc. Am. 87, 1502-1521.

Bollinger, L., J. P. Avouac, R. Cattin, M. R. Pandey (2004). Stress buildup in the Himalaya, J. Geophys. Res.109, B11405, doi:10.1029/2003JB002911.

Dieterich J. H. (1994). A constitutive law for rate of earthquake production and its application to earthquake clustering, J. Geophys. Res. 99, 2601-2618.

Dieterich J. H. \& Kilgore B. (1996) Implications of fault constitutive properties for earthquake prediction, Proc. Nat. Acad. of Sci. USA 93, 3787-3794.

Cocco M., Hainzl S., Catalli, F. Enescu, B. Lombardi, A.M. et al. (2010) Sensitivity study of forecasted aftershock seismicity based on Coulomb stress calculation and rate- and statedependent frictional response, J. Geophys. Res. 115, B05307, 10.1029/2009JB006838.

Console, R., Murru M. and G. Falcone (2010). Pertubation of earthquake probability for interacting faults by static Coulomb stress changes, J. Seis., 14(1). 67-77.

Hardebeck, J. L. (2004). Stress triggering and earthquake probability estimates, J. Geophys. Res., 109, B04310, doi:10.1029/2003JB002437.

Hardebeck, J. L. (2014) The impact of static stress change, dynamic stress change, and the background stress on aftershock focal mechanisms, J. Geophys. Res. 119, 8239-8266, doi:10.1002/2014JB011533.

Harris R. A. (1998). Introduction to special section: stress triggers, stress shadows, and implications for seismic hazard, J. Geophys. Res. 103, 24,347-24-358.

Harris R. A. \& Simpson R. W. (1996). In the shadow of 1857 - the effect of the great Ft. Tejon earthquake on subsequent earthquakes in Southern California, Geophys. Res. Lett. 23, 229232.

Helmstetter A. (2003) Is earthquake triggering driven by small earthquakes?, Phys. Rev. Lett. 91, 585011-585014.

Jaeger, J. C. \& Cook, N. G. W. (1976). Fundamentals of Rock Mechanics, Chapman and Hall, London, England.

Jordan, T. H., Y.T. Chen, P. Gasparini, R. Madariaga, I. Main, W. Marzocchi, G. Papadopoulos, G. Sobolev, K. Yamaoka and J. Zschau (2011). Operational Earthquake Forecasting. State of Knowledge and Guidelines for Utilization. Annals of Geophysics, 54(4), doi:10.4401/ag-5350.

Jouanne, F., Mugnier, J.L., Gamond, J.F., Le Fort, P., Pandey, M.R. et al., (2004).Current shortening across the Himalayas of Nepal, Geophys. J. Int. 157, 1-14

Kagan, Y. Y. (2003). Accuracy of modern global earthquake catalogs, Phys. Earth Planet. Int. 135, 173-209 (2003).

King, G. C. P. and Stein, R. S. and Lin, J. (1994). Static stress changes and the triggering of earthquakes, Bull. Seismol. Soc. Am. 84, 935-953. 
Mallman E. P. and Zoback M. D. (2007). Assessing elastic Coulomb stress transfer models using seismicity rates in southern California and southwestern Japan, J. Geophys. Res. 112, B03304, doi:10.1029/2005JB004076.

Mallman, E. P. and Parsons, T. (2008). A global search for stress shadows, J. Geophys. Res. 113, doi:10.1029/2007JB005336.

Martin S. and Szeliga, W. (2010). A catalog of felt intensity data for 570 earthquakes in India from 1636 to 2009, Bull. Seismol. Soc. Am. 100, 562-569.

Nanjo K. Z., Tsuruoka, H. Yokoi, S., Ogata, Y., Falcone, G. et al. (2012). Predictability study on the aftershock sequence following the 2011 Tohoku-Oki, Japan, earthquake: first results, Geophys. J. Int. 191, 653-658.

National Society for Earthquake Technology-Nepal (NSET) (2010). Shelter response strategy and plan for earthquake disasters for Kathmandu Valley, Nepal, $60 \mathrm{pp}$.

Ogata Y. (1988) Statistical models for earthquake occurrences and residual analysis for point processes, J. Amer. Statist. Assoc. 83, 9-27.

Ogata Y. (1998) Space-time point-process models for earthquake occurrences, Ann. Inst. Stat. Math. 50, 379-402.

Omori F. (1894) On aftershocks, Report of Imperial Earthquake Investigation Committee 2, 103 109.

Parsons, T., Toda, S., Stein, R. S., Barka, A., and Dieterich, J. H. (2000). Heightened odds of large earthquakes near Istanbul: an interaction-based probability calculation, Science 288, 661-665.

Parsons, T. (2005). Significance of stress transfer in time-dependent earthquake probability calculations,J. Geophys. Res. 110, B05S02, doi:10.1029/2004JB003190.

Parsons, T., Ji C. \& Kirby E. (2008). Stress changes from the 2008 Wenchuan earthquake and increased hazard in the Sichuan basin, Nature 454, 509-510.

Parsons, T., Ogata, Y., Zhuang, J. \& Geist, E. L. (2012) Evaluation of static stress change forecasting with prospective and blind tests, Geophys. J. Int. 188, 1425-1440, doi: 10.1111/j.1365-246X.2011.05343.x.

Parsons, T. \& Segou M. (2014). Stress, distance, magnitude, and clustering influences on the success or failure of an aftershock forecast: the $2013 M=6.6$ Lushan Earthquake and other examples, Seis. Res. Lett. 85, 44-51.

Rajendran, C. P., John B. and Rajendran K. (2015). Medieval pulse of great earthquakes in the central Himalaya: viewing past activities on the frontal thrust, J. Geophys. Res. 120.

Rhoades, D.A., D. Schorlemmer, M.C. Gerstenberger, A. Christophersen, J.D. Zechar, and M. Imoto (2011). Efficient testing of earthquake forecasting models, Acta Geophysica 59, 728 747, doi:10.2478/s11600-011-0013-5.

Sapkota S. N., Bollinger, L., Klinger, Y., Tapponier, P. and Gaudemer, Y. et al. (2013). Primary surface ruptures of the great Himalayan earthquakes in 1934 and 1255, Nature Geosci. 6, 7176.

Schorlemmer, D., Gerstenberger, M.C., Wiemer, S., Jackson, D.D., Rhoades, D.A. (2007). Earthquake likelihood model testing, Seismol. Res. Lett. 78, 17-29.

Segou, M. Parsons, T. and Ellsworth, W.(2014). Comparative evaluation of physics-based and statistical forecasts in Northern California, J. Geophys. Res. 118, 6219-6240, doi:10.1002/2013JB010313 
Sornette D. \& Werner M. J. (2005) Constraints on the size of the smallest triggering earthquake from the epidemic-type aftershock sequence model, Båth's law, and observed aftershock sequences, J. Geophys. Res. 110, B08304, doi 10.1029/2004JB003535.

Strader, A., and D. D. Jackson (2015), Static Coulomb stress-based Southern California earthquake forecasts: A pseudoprospective test, J. Geophys. Res. Solid Earth, 120, 1667-1676, doi:10.1002/2014JB011297.

Stein, R. S. (1999). The role of stress transfer in earthquake occurrence, Nature 402, 605-609.

Stramondo S., Christodoulos, K. Bignami, C., Chini, M. Melini D. et al. (2011) Did the September 2010 (Darfield) earthquake trigger the February 2011 (Christchurch) event?, Scientific Reports 1, Article number 98.

Toda, S., Stein, R. S., Richards-Dinger, K. \& Bozkurt, S. (2005). Forecasting the evolution of seismicity in southern California: animations built on earthquake stress transfer, J. Geophys. Res. 110, B05S16, doi:10.1029/2004JB003415.

Toda S. \& Enescu, B. (2011). Rate/state Coulomb stress transfer model for the CSEP Japan seismicity forecast, Earth Planets Space 63, 171-185.

Utsu T. (1961). Statistical study on the occurrence of aftershocks, Geophys. Mag. 30, 521-605.

Wobus, C., Heimsath, A., Whipple, K. \& Hodges, K. (2005). Active out-of-sequence thrust faulting in the central Nepalese Himalaya, Nature 434, 1008-1011.

Woessner, J., S. Hainzl, W. Marzocchi, M. J. Werner, A.M. Lombardi et al. (2011), A Retrospective Comparative Forecast Test on the 1992 Landers Sequence, J. Geophys. Res., B05305, doi:10.1029/2010JB007846.

Yeats R. S., T. Nakata, A. Farah, M. Fort, M.A. Mirza et al., The Himalayan frontal fault system, Annales Tectonicae VI, 85-98 (1992).

Zechar, J. D., Gerstenberger, M. C., Rhoades, D. A. (2010). Likelihood-based tests for evaluating space-rate-magnitude earthquake forecasts, Bull. Seismol. Soc. Am. 100, 1184-1195.

FIGURES

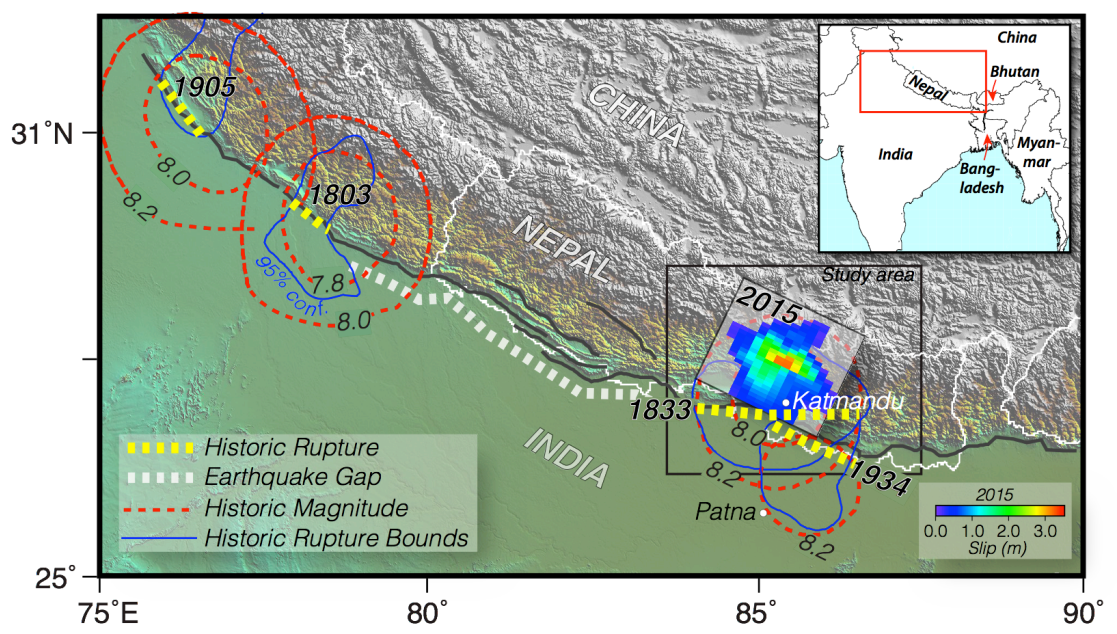


Fig. 1. Setting of the 25 April $2015 M=7.8$ earthquake in Nepal. The rupture plane (dipping $10^{\circ}$ down to the northeast) and slip distribution, provided by USGS $^{3}$, are shown in relation to historic ruptures (yellow dashed lines give possible rupture ranges, and not necessarily rupture lengths). Blue lines show $95 \%$ confidence bounds on rupture locations and red contours give magnitude vs. epicenter location. Large $(M \sim 8)$ earthquakes have clustered near the east end of a broad seismic gap (white dashed line) at the central Himalayan front that has not ruptured since AD1255-1505 (see Historic earthquake location section, available in the electronic supplement to this article).
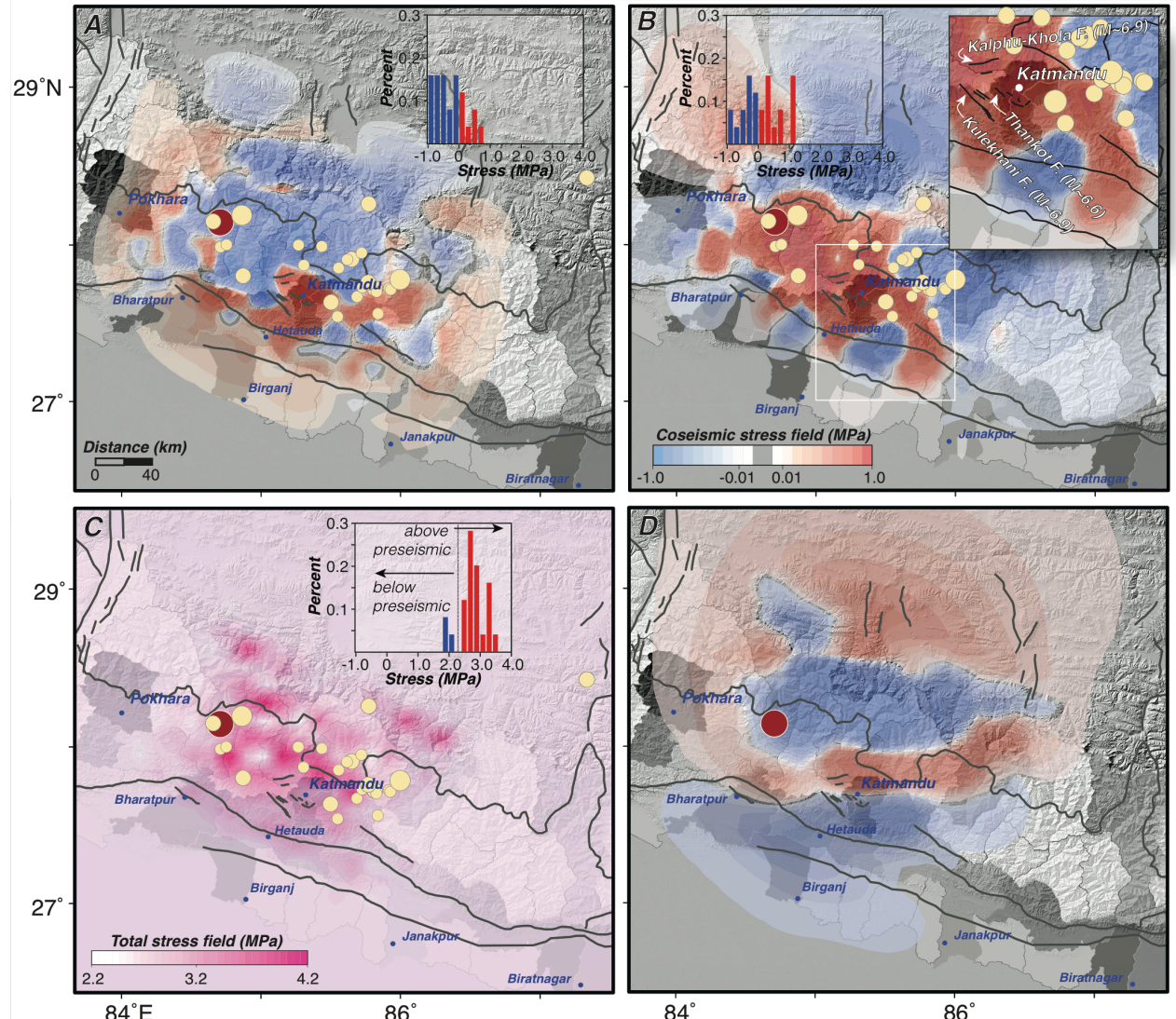

Fig. 2. Calculated Coulomb stress change distribution from different methods. Triggered earthquakes above the magnitude completeness level of $M \geq 4.7$ are shown as dots, and the mainshock as a red dot. Relative population density by prefecture in Nepal is shown, with densest areas shaded more darkly. Histograms show the number of triggered events in stress-increased and stress-

\footnotetext{
${ }^{3} \mathrm{http}: / /$ earthquake.usgs.gov/earthquakes/eventpage/us20002926\#scientific finitefault http://earthquake.usgs.gov/earthquakes/eventpage/us20002ejl\#scientific finitefault
} 
decreased areas. Major faults are shown as black lines. (a) Stress changes are resolved on planes parallel to the mainshock rupture at $10 \mathrm{~km}$ depth. (b) Stress changes are resolved on faults optimally orientated to a horizontal greatest stress direction of $\mathrm{N} 19^{\circ} \mathrm{E}$ at $10 \mathrm{~km}$ depth. A close-up of the Katmandu basin and local faults with maximum magnitude assignments is shown. (c) Total stress (preseismic and coseismic change) resolved at $10 \mathrm{~km}$ depth on planes most favorable to resultant principal stress directions and magnitudes. (d) Stress changes resolved on the decollement fault that extends north beneath the Himalayas.
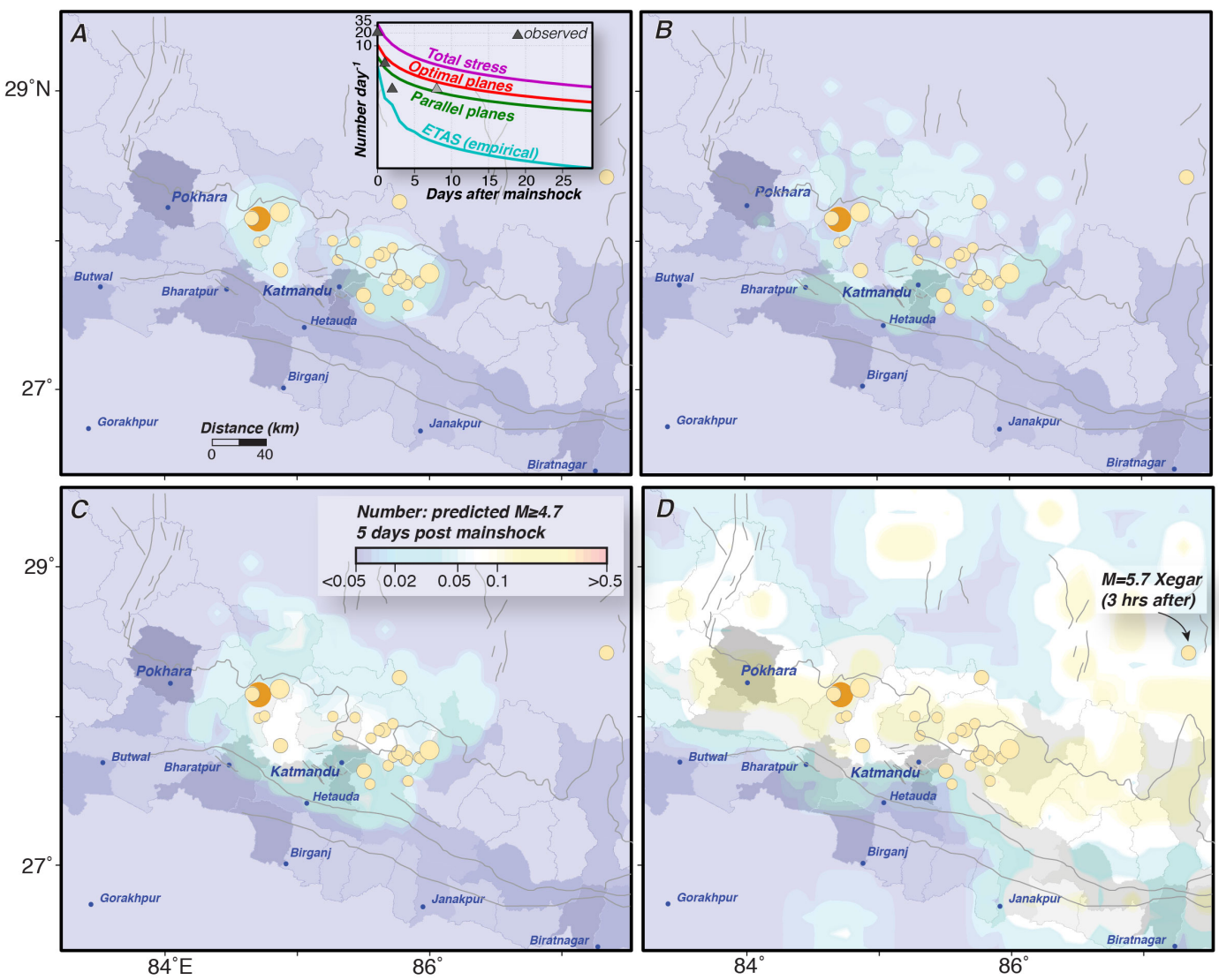

Fig. 3. Five-day forecast comparisons. Contours show expected numbers of $M \geq 4.7$ events, and the actual distribution of triggered earthquakes is plotted. (a) The statistical forecast is spatially limited because it depends on precursory earthquakes. The inset shows the 30-day forecast; dark triangles represent events used to tune the statistical forecast, and the lighter triangle shows a subsequent rate. (b) A forecast based on stress changes resolved on planes parallel to the mainshock is improved relative to the statistical method, but still underreports the first days of seismicity. Forecasts based on (c) optimal fault orientations and (d) the complete stress tensor bracket observed $M \geq 4.7$ rates, with the total stress 
method forecasting a much wider area that captures the $M=5.7$ Xegar shock, located $\sim 245 \mathrm{~km}$ east of the mainshock.

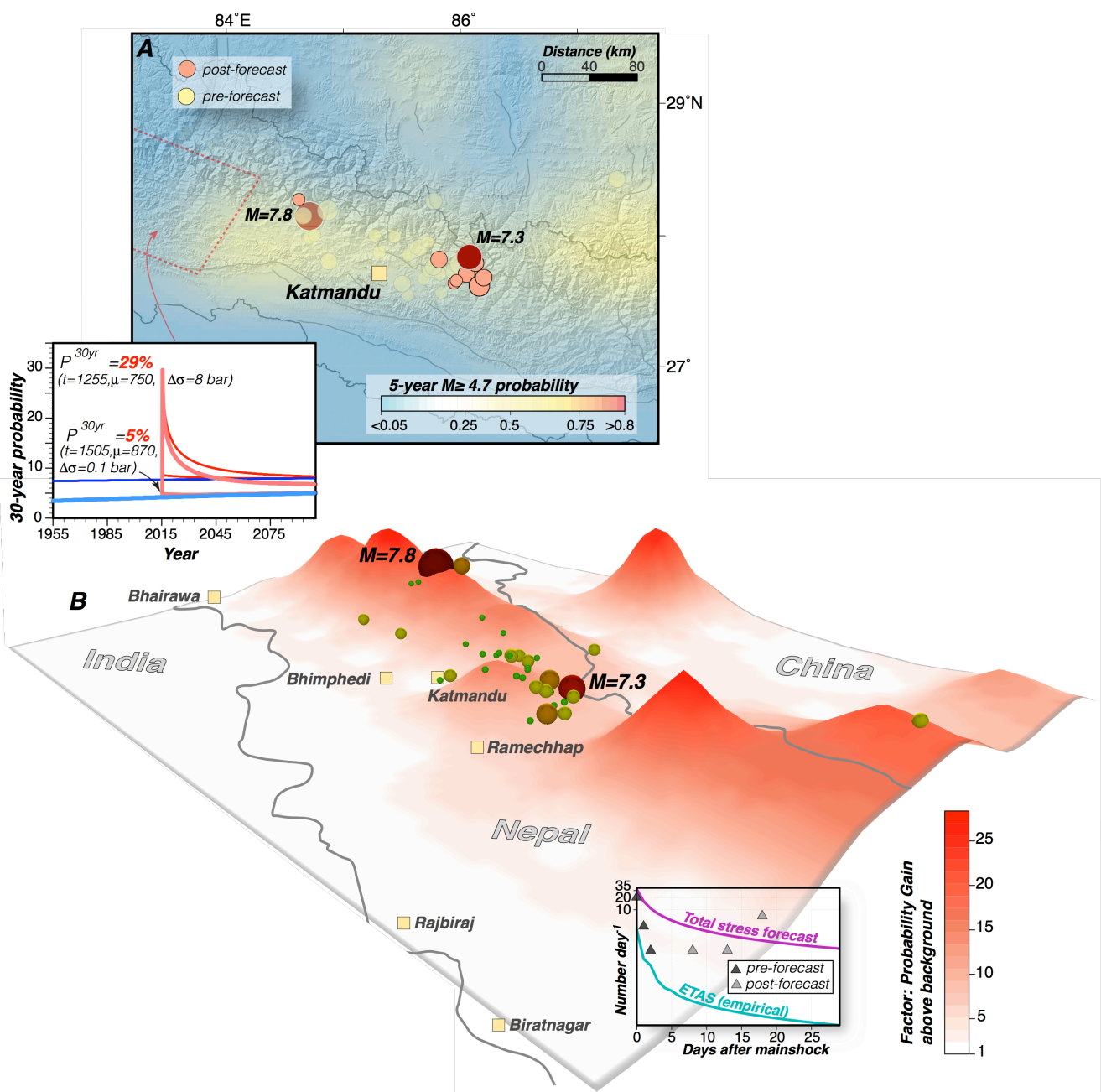

Fig. 4. Five year probabilistic forecast for the Katmandu region and affected areas along the Himalayan front. (a) 5-yr $M \geq 4.7$ Probability calculated before 9 May 2015 is contoured. A band of heightened probability tracks along the Himalayan front that is of particular concern at the seismic gap west of the 25 April $2015 M=7.8$ mainshock. The lower inset shows time dependent probability (Method) vs. year specific to stress-increased parts of the main boundary thrust range reach a maximum of $29 \%$ (increased from $5-8 \%$ ) in the next 30 years. (b) Ratio of 5-year $M \geq 4.7$ earthquake probability to background level is shown as a contour surface to illustrate most likely future earthquakes sites. The 12 May $M=7.3$ shock and all other $M \geq 4.7$ events (spheres) fell within areas of $\geq 5$-fold gain. Comparative 30-day forecast rate decay vs. time curves (calculated using 
first 5 days of observed seismicity) are shown with updated observations that include the 12 May $M=7.3$ shock.

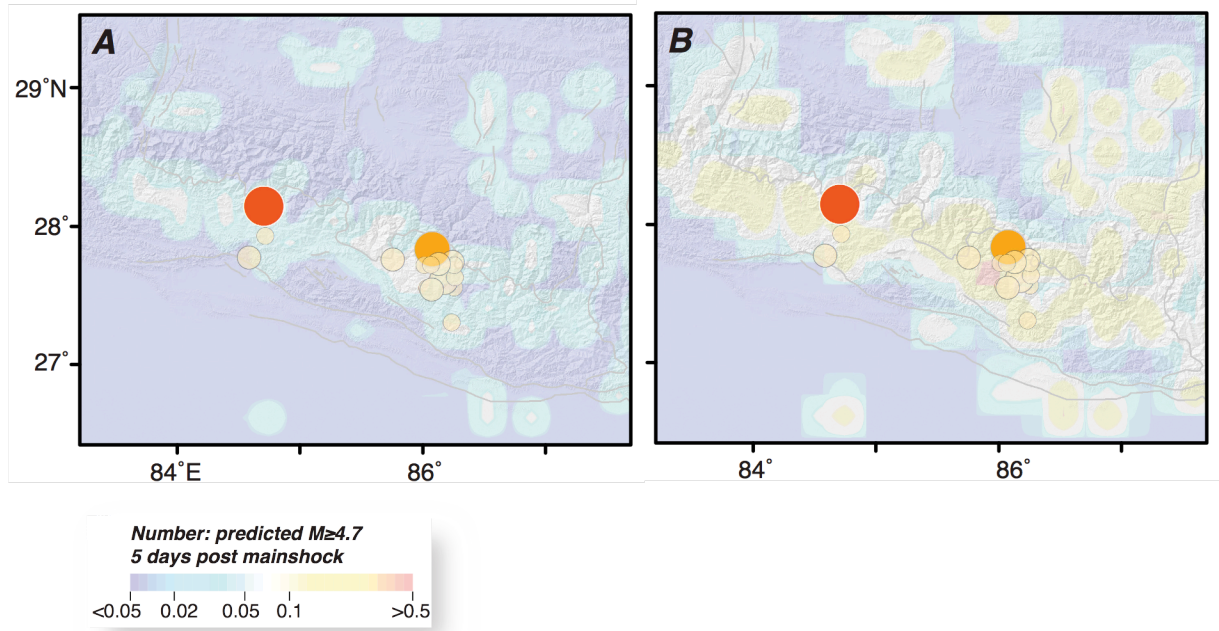

Fig. 5. Five day forecast comparison. Contours show expected numbers of $M \geq$ 4.7 events, and the actual distribution of triggered earthquakes is plotted for the first 5 days following the $M=7.3$ triggered event (12/05/2015 07:05:19 UTC). The initial and updated forecast, based on the total stress methos, incorporate (a) coseismic stress changes only by the $M=7.8$ mainshock and (b) additional stress changes by the $M=7.3$ triggered event. 


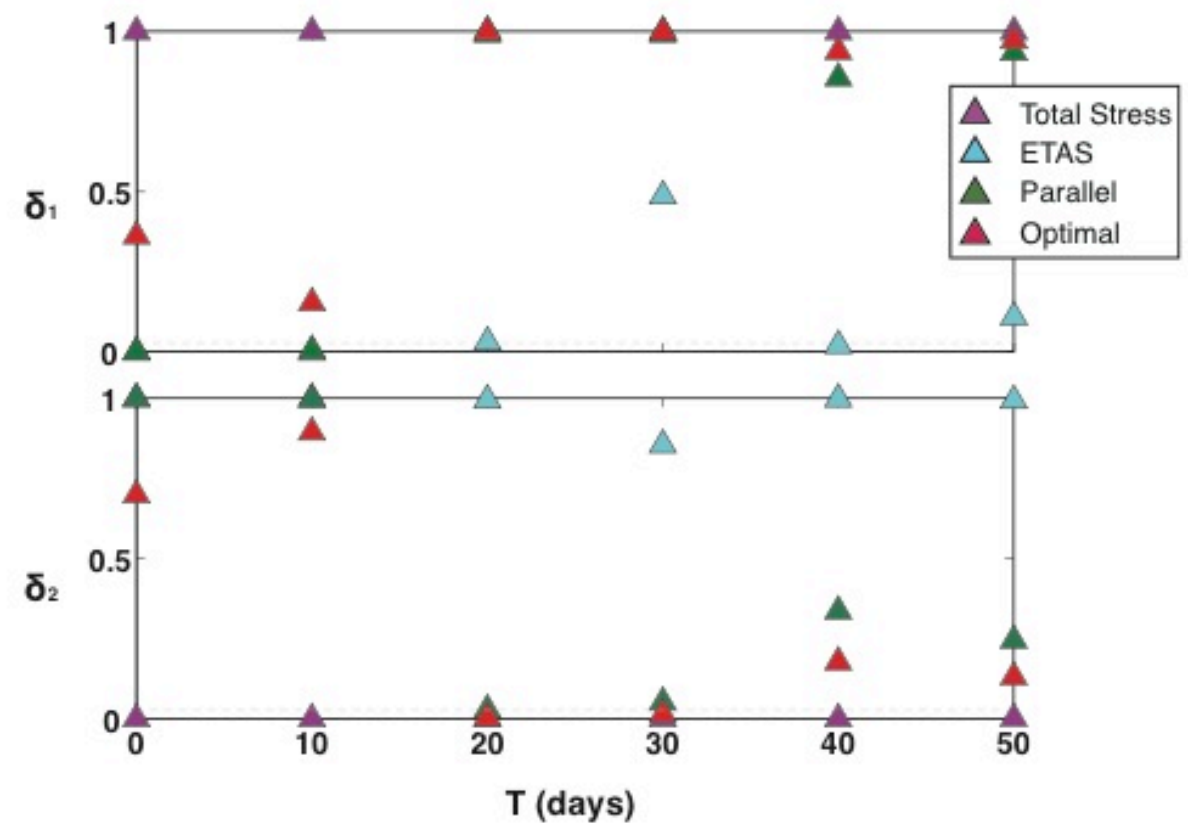

Fig. 6. Absolute performance evaluation of forecast models. Quantile scores of $\delta_{1}$ and $\delta_{2}$ of the $N$-test as a function of time evaluated within 10-day intervals. Gray dashed line indicates the 0.05 significance level at which a forecast is rejected. Small $\delta_{1}$ and $\delta_{2}$ values correspond to underestimation and overestimation of the observed seismicity by a forecast model, respectively. The benchmark ETAS model underestimates observed seismicity through the entire testing period, and the model from stress changes resolved on parallel faults also suffers for the same reason at the early stages of the sequence, whereas the total-stress and the optimal planes method show signs of overestimation. 
a

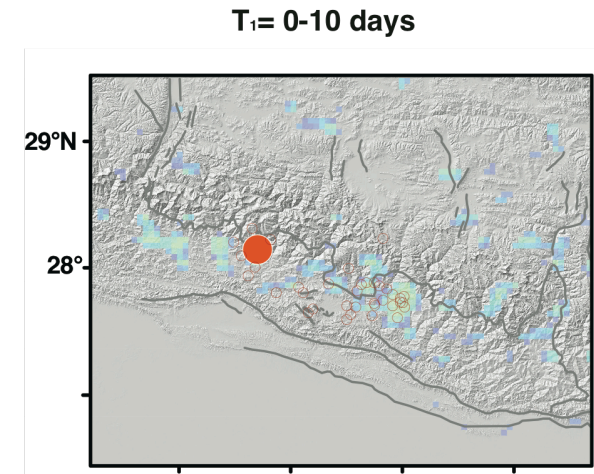

b

C
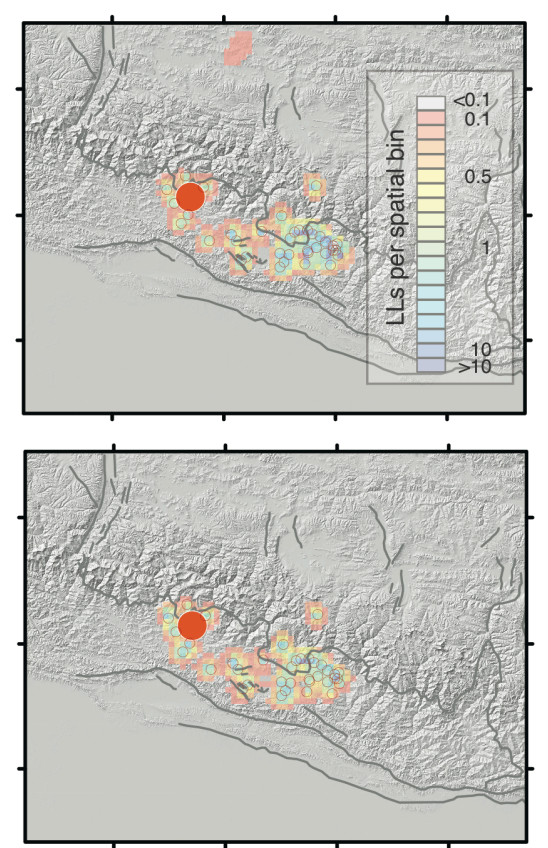

d

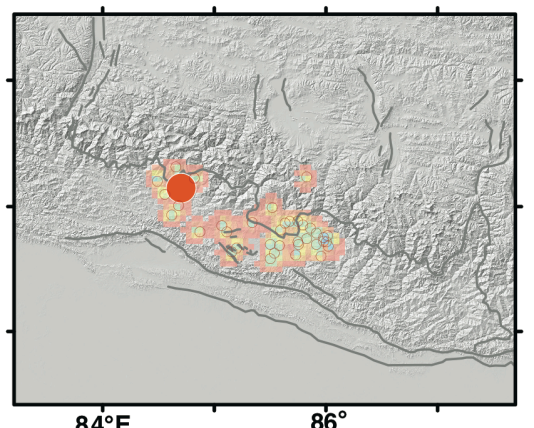

$T_{2}=10-20$ days

a

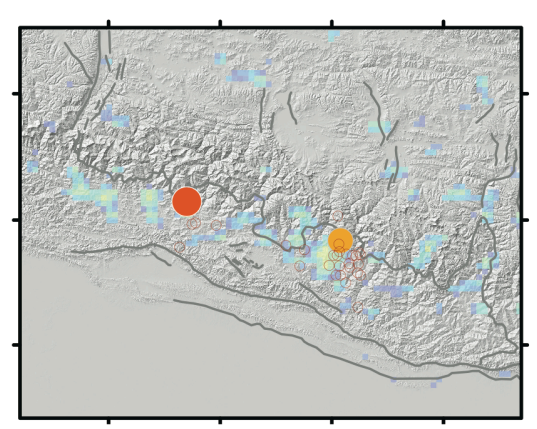

$b$

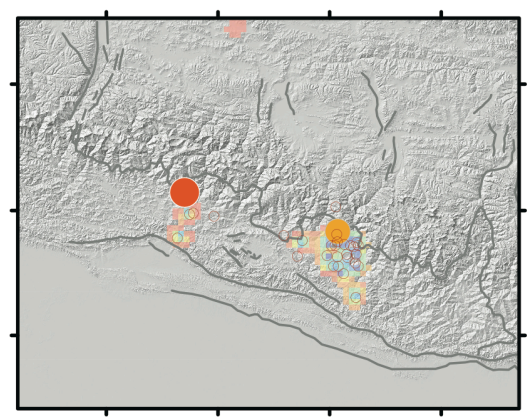

c

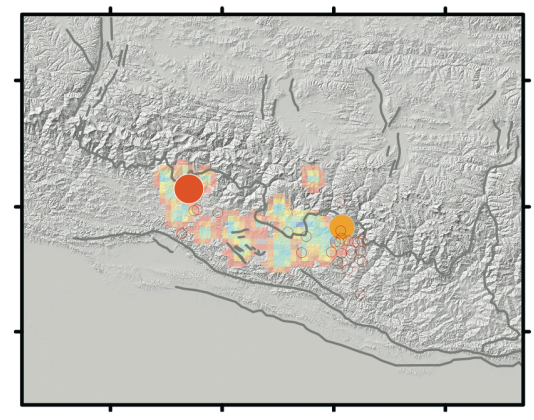

$d$

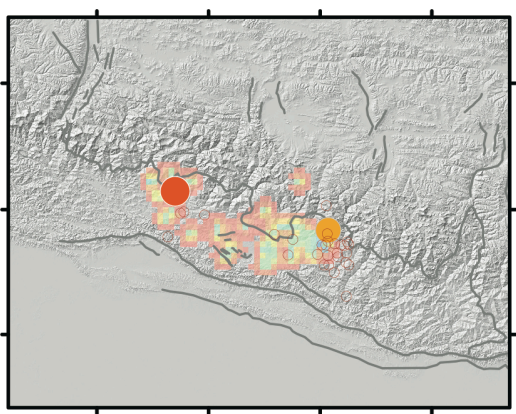

Fig. 7. Relative Performance evaluation of forecast models. Triggered earthquakes above the magnitude of completeness of $M \geq 4.7$ are shown as dots. Major faults are shown as black lines. Maps of log likelihood at each spatial bin 


\section{Electronic Supplement to \\ 3 Prospective earthquake forecasts at the Himalayan front after 4 the 25 April $2015 M=7.8$ Gorkha mainshock}

2

\section{By M. Segou and T. Parsons}

The electronic supplement (Part A) focuses on Historic earthquake location, the implementation of Epidemic Type Aftershock Sequence, the Conversion of Stress Changes in Forecast Earthquake Rates, an example of San Francisco Bay area related to the Total Stress method implementation [Figure S1], a short-term forecast evaluation of the predictability of the forecast models using Performance evaluation metrics, such as information gain [Figure S2] together with a long-term (6 months) evaluation [Figure S3]. At the second part of this electronic supplement (Part B) we present the original forecast as of 9 May, 2015 (56 hours before the 12 May $2015 M=7.3$ aftershock).

\section{PART A}

Historic earthquake location. We calculate historic earthquake locations from historical

20 intensity observations (Bakun and Wentworth, 1997; Martin and Szelinga, 2010). The

21 method performs a grid search for trial epicenters $(5 \mathrm{~km}$ spacing in east and north

22 directions) and, using an empirical intensity attenuation relation vs. distance, locates the

23 region where $95 \%$ of trial epicenters minimize root mean square (RMS) misfits to observed

24 intensity values.

26 Epidemic Type Aftershock Sequence (ETAS) implementation. Short-term statistical

27 earthquake forecasts built on the idea that each earthquake triggers a number of off-spring

28 events, relative to its magnitude, and on empirical laws such as the Omori law decay and

29 the Gutenberg-Richter magnitude frequency distribution. Here, we allow the ETAS (Ogata,

30 1988; Ogata, 1998) model to use all available earthquakes to achieve optimum

31 performance although the Nepal catalog is complete to $M \geq 4.7$. To estimate the necessary 
32 parameters, we use equations for estimating the apparent fraction $n_{a}$ with respect to the 33 real fraction of triggered events $n$ (Sornette and Werner, 2005). time seismicity rate $\lambda(x, y, t)$ is given by:

$$
\lambda(x, y, t)=\mu(x, y)+\sum_{i: t_{i<t}} \frac{K e^{\alpha\left(M_{i}-M_{t h}\right)}}{\left(t-t_{i}+c\right)^{p}} f_{i}\left(x-x_{i}, y-y_{i} ; M_{i}\right)
$$

with $f(x, y ; M)=\frac{q-1}{\pi D(M)}\left(1+\frac{x^{2}+y^{2}}{D(M)}\right)^{-q}$

$40 M_{\text {min }}=4.7, m_{d}=4.0, \alpha=0.7, b=1.0, n=0.67, n_{a}=0.51, k=0.2167, c=0.002$ day. Parameter $\mu(x, y)$ is the

41 background rate, $c$, and $p$ are Omori-law values governing the decay rate of aftershocks, $\alpha$

42 estimates the magnitude efficiency of an earthquake in generating its offspring; $d, \gamma$ and $q$

$43\left(\mathrm{~d}=0.0071 \mathrm{deg}^{2}, \mathrm{q}=1.96, \gamma=0.7\right)$ are spatial fitting parameters in close agreement with parameters

44 from similar seismotectonic environments (Parsons and Segou, 2014).

45 For the favorable case of lower magnitude scaling formulation with $\alpha<b=1.0$, the apparent

46 branching ratio $n_{a}$ is given by the equation

$47 \quad n_{a}=\frac{k b \ln (10)\left(M_{\max }-m_{d}\right)}{1-10^{-b\left(M_{\max }-M_{\min }\right)}} \quad$ and the relation between $n$ and $n_{a}$ is

$48 \quad n_{a}=n\left(\frac{10^{(b-a)\left(M_{\max }-m_{d}\right)_{-1}}}{10^{(b-a)\left(M_{\max }-M_{\min }\right)_{-1}}}\right)$, where $m_{d}$ is the detection threshold and $M_{\min }$ the minimum

49 triggering threshold. 
52 Conversion of stress changes to forecast earthquake rates. Following the rate-and-

53 state friction framework (Dieterich, 1994; Dieterich, 1996) the pre-mainshock earthquake

54 activity

$\mathrm{R}$

as

$$
R=\frac{r}{\gamma \dot{\tau}}
$$

where

$55 \gamma_{n}=\gamma_{n-1} \exp \left(\frac{-\Delta C F F}{\mathrm{~A} \sigma}\right)$, is suppressed or enhanced by static stress changes.

56

57 The time-dependent seismicity rate $R(t)$ is a function of state variable $\mathrm{y}$ after a stress perturbation

$58 \gamma_{n+1}=\left[\gamma_{n}-\frac{1}{\dot{i}}\right] \exp \left[\frac{-\Delta t \dot{t}}{\mathrm{~A} \sigma}\right]+\frac{1}{\dot{i}}$ where $r$ is the steady-state seismicity rate, $\Delta \mathrm{CFF}$ is the stress

59 step, aftershock duration $t_{a}$ is assumed to be 25 years, and daily forecast parameters are: $a \sigma=0.5$

60 (Toda and Enescu, 2011) and $\dot{\tau}=0.00239 \mathrm{MPa} / \mathrm{yr}$, based on regional thrust fault slip rates of $\sim 10$

$61 \mathrm{~mm} / \mathrm{yr}$ (Ader et al., 2012). $R(t)$ is related to earthquake probability over the interval $\Delta t$ as

$62 P(t, \Delta t)=1-\exp \left[-\int_{t}^{t+\Delta t} R(t) d t\right]=1-\exp (-N(t))$

63 where $N(t)$ is expressed as

$$
N(t)=r_{p}\left\{\Delta t+t_{\alpha} \ln \left[\frac{1+\left[\exp \left(\frac{-\Delta C F F}{A \sigma}\right)-1\right] \exp \left[\frac{-\Delta t}{t_{\alpha}}\right]}{\exp \left(\frac{-\Delta C F F}{A \sigma}\right)}\right]\right\}
$$

64

65 and $r_{p}=\left(\frac{-1}{\Delta t}\right) \ln \left(1-P_{c}\right)$, where $P c$ is a conditional probability.

66

\section{Performance evaluation metrics}

68 The modified $N$-test (Zechar et al., 2010) evaluates the consistency between the total number

69 of predicted and observed events within the area of interest. This test is based on the equations,

$70 \delta_{1}=1-F\left(N_{O b s}-1 \mid N_{F}\right)$ and $\delta_{2}=F\left(N_{O b s} \mid N_{F}\right)$, where $F(x \mid \mu)$ is the right-continuous Poisson 
71 cumulative distribution function with expectation $\mu$ evaluated at $x$. and $\mathrm{N}_{\mathrm{F}}$ is the forecast

72 number of events determined by the model. The quantiles $\delta_{1}$ and $\delta_{2}$ answer two questions under

73 the assumption that the forecast is correct: (1) What is the probability of observing at least $N_{\text {obs }}$

74 events? And (2) what is the probability of observing at most $N_{o b s}$ earthquakes? These metrics

75 share a complimentary role $\delta_{1} \simeq 1-\delta_{2}$ suggesting a forecast be rejected if either $\delta_{1}(t)<\alpha_{e f f}$

76 or $\delta_{2}(t)<\alpha_{e f f}$, where $\mathrm{a}_{e f f}=0.025$ corresponds to the effective significance value. In Fig. S2 we

77 show the results of the $N$-test within 10-day time windows.

79 The $S$-test (Zechar et al., 2010) aims to compare the relative spatial performance of the

80 forecast model using log-likelihood statistics estimated over 1000 simulations. The log-

81 likelihood $L$ of observing $\omega$ events at a given expectation $\lambda$ for a model $j$ is defined by the the

82 logarithm of the probability $p(\omega \mid \lambda)$ expressed by

83

$$
L\left(\omega \mid \lambda^{j}\right)=\log p\left(\omega \mid \lambda^{j}\right)=-\lambda^{j}+\omega \log \lambda^{j}-\log \omega !
$$

84

and,

$$
L(\Omega \mid \Lambda)=\sum_{(i, j \mathcal{E} R)}(-\lambda(i, j)+\omega(i, j) \log (\lambda(i, j))-\log (\omega(i, j) !))
$$

85

86 in the case of the joint log-likelihood, which represents the sum of log-likelihood values over all

87 bins $b_{i}$. We present in Fig. S3 maps of the log-likelihood per spatial bin for the time intervals 0-

$88 \quad 10$ and 10-20 days, respectively. 
The $T$-test (Rhoades et al., 2011) evaluates the sample information gain per earthquake of a model $A$ over model $B$ defined by
$\mathrm{I}_{\mathrm{N}}(A, B)=\frac{1}{N} \sum_{i=1}^{\mathrm{N}}\left(X_{i}-\Upsilon_{i}\right)-\frac{\widehat{\mathrm{N}}_{A}-\widehat{N}_{B}}{N}$
(6), where $I_{N}(A, B)$ is considered as the mean of a

sample from a population with actual mean $I(A, B)$, where $I_{N}(A, B)$ is the true information gain of model $A$ over model $B$ with with $X_{i}=\log \lambda_{A}(i)$ and $Y_{i}=\log \lambda_{B}(i)$ the $\log$-likelihood value of a model $A$ and $B$ in the $i^{\text {th }}$ bin. Here, we use the statistical model as reference model due to the simplicity of this implementation. We present in Fig. S4, the mean and the $95 \%$ confidence interval of the information gain per model for the time intervals used in our spatial mapping of log-likelihood.

9




\section{PART B}

128 Prospective forecast as of 9 May, 2015 (56 hours before the 12 May 2015 M=7.3 129 aftershock).

131 This is the original rapid forecast that was completed 2 weeks after the 25 April $M=7.8$ Nepal 132 mainshock. It is followed by an email confirming the submission time before the 12 May $M=7.3$ 133 aftershock. 
within 0-10 (left panel) and 10-20 days (right panel) are shown for the (a,a) complete stress tensor forecast, $(\mathbf{b}, \boldsymbol{b})$ statistical model, $(\mathbf{c}, \boldsymbol{c})$ physics forecast based on planes parallel to the mainshock rupture, $(\mathbf{d}, \boldsymbol{d})$ physics forecast based on optimal fault orientations. The sum of log-likelihood at the end of the evaluation phase (0-20 days) at the location of Kodari $M=7.3$ (12/05/2015 07:05:19 UTC) triggered event, noted as an orange circle in the right panel, is associated with smaller log-likelihood values for the complete stress tensor forecast model, indicating good performance $\left(\mathrm{LL}_{\mathrm{s}}{ }^{\mathrm{A}}:-2.0616, \mathrm{LL}_{\mathrm{s}}^{\mathrm{B}}\right.$ : $-11.336, \mathrm{LL}_{\mathrm{s}}{ }^{\mathrm{C}}:-2.7621, \mathrm{LL}_{\mathrm{s}}{ }^{\mathrm{D}}$ : - 2.7592). 

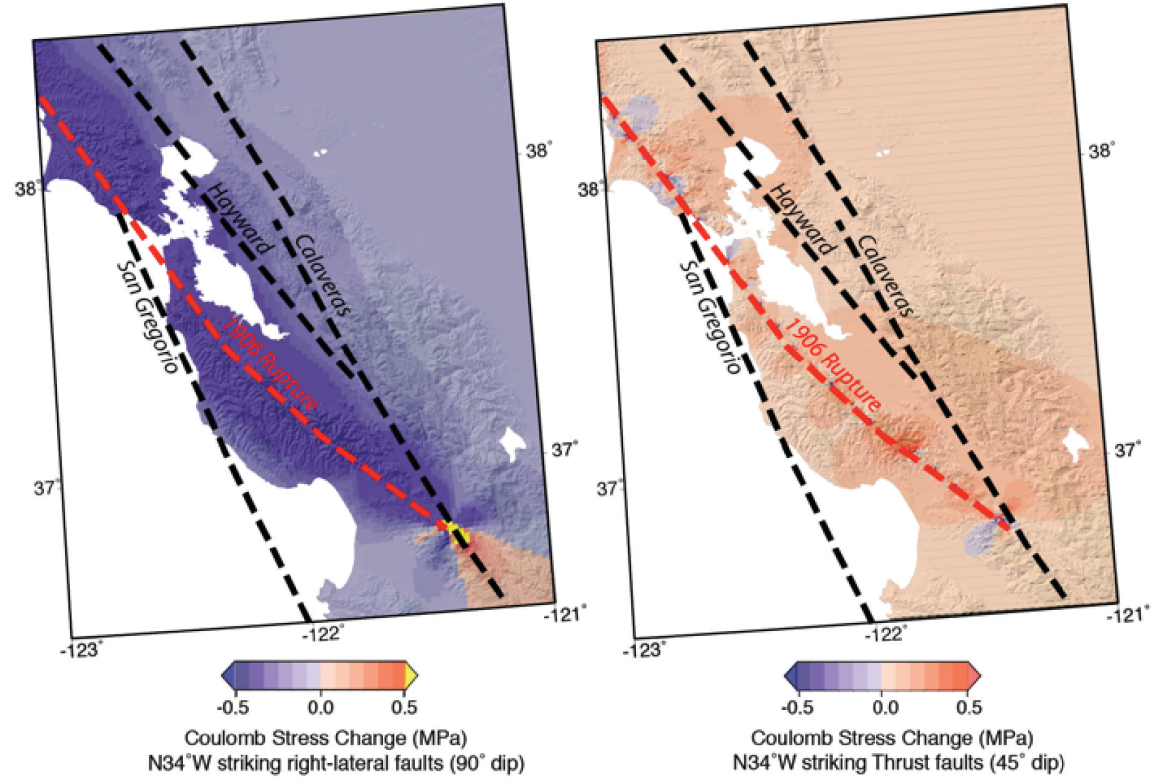

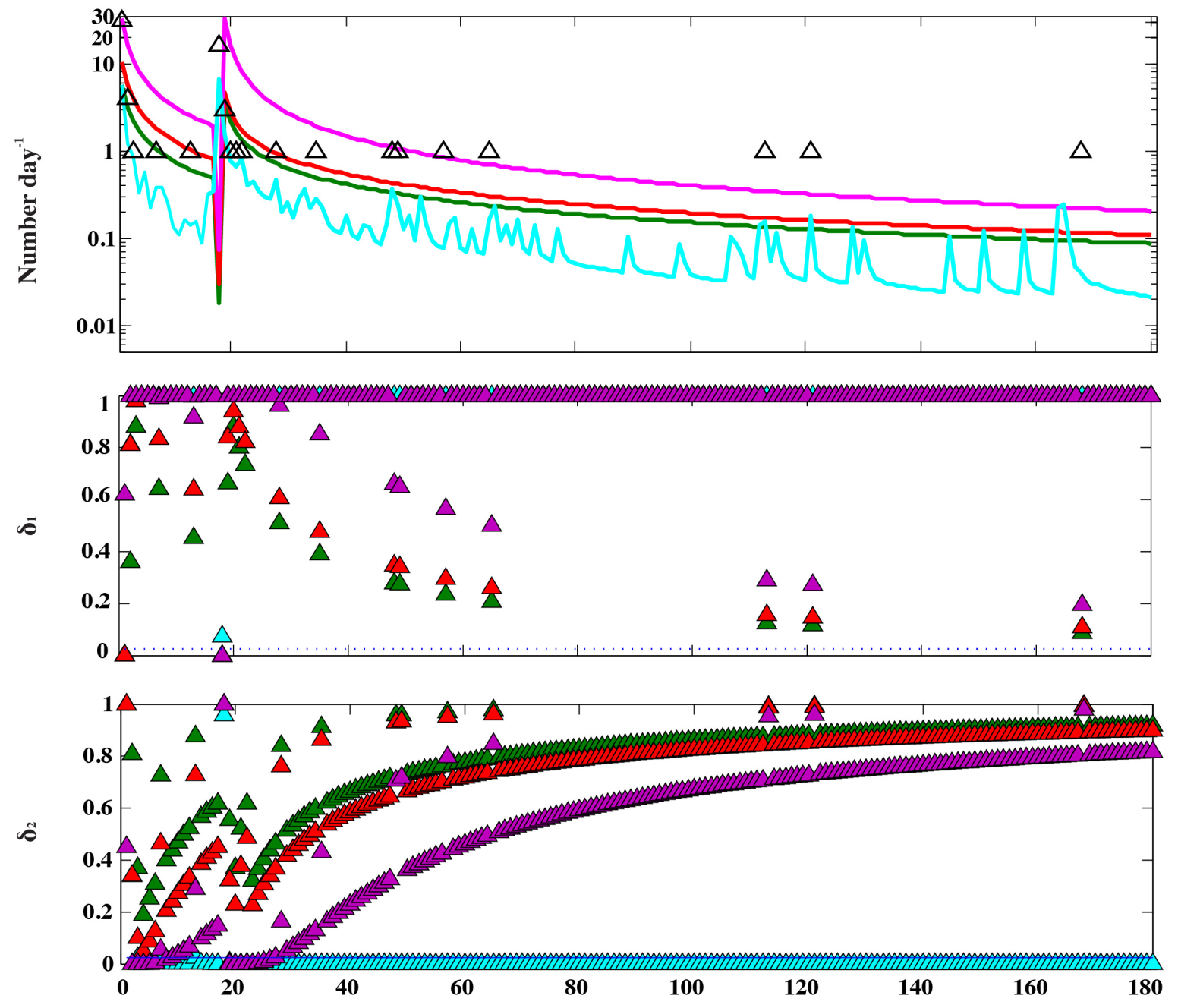

Days after mainshock 
a

Reverence Model: ETAS

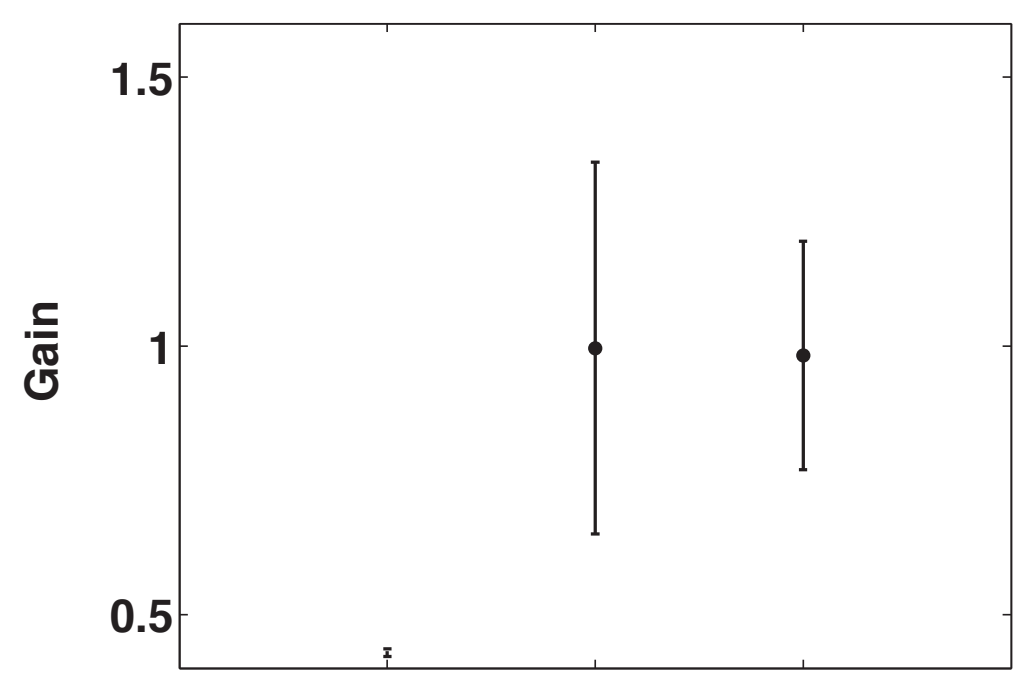

b

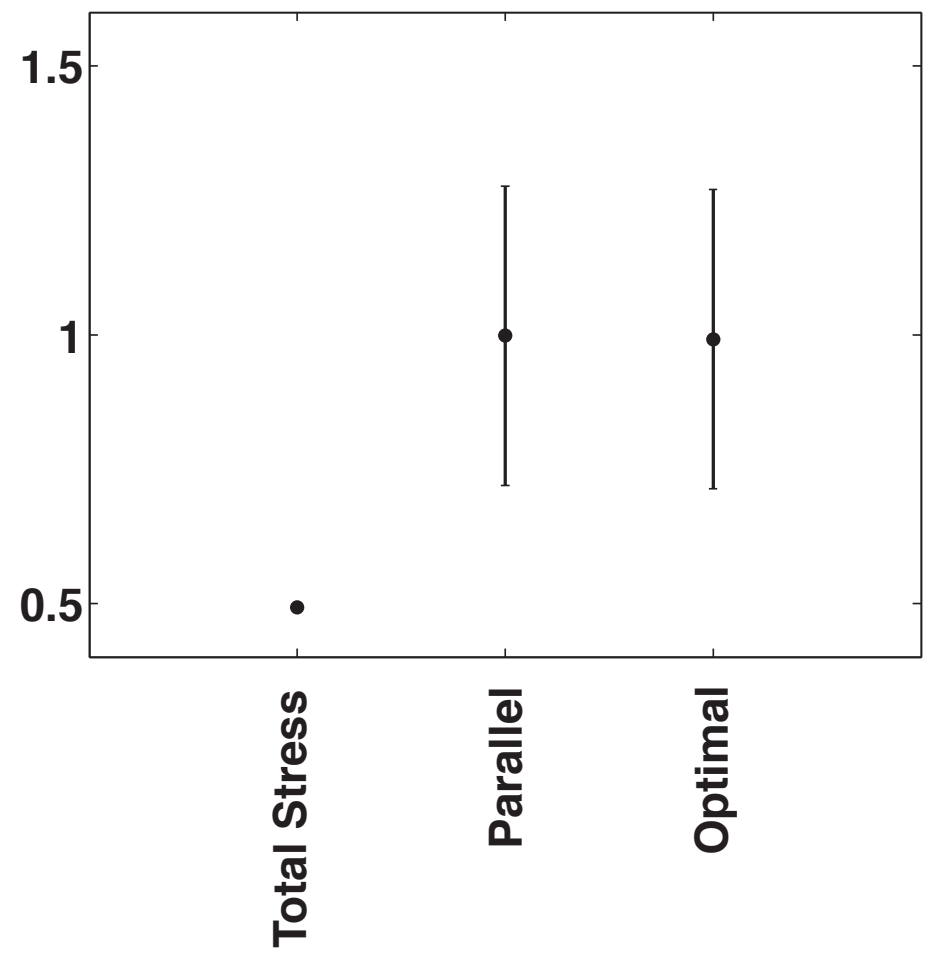


Impending earthquakes beneath Katmandu and the Himalayan front after the 25 April 2015 M=7.8 Nepal mainshock

M. Segou and T. Parsons

U.S. Geological Survey, Menlo Park, California

When a major earthquake strikes, the resulting devastation is compounded or even exceeded by the subsequent cascade of triggered seismicity. As the Nepalese begin recovery from the 25 April 2015 shock, knowledge of what comes next is essential. We calculate the redistribution of crustal stresses and earthquake probabilities for different time horizons from daily to 30 years into the future. The odds of moderate to large earthquakes affecting Katmandu reach $90 \%$, and exceed $50 \%$ for the Himalayan front in eastern Nepal. The probability of a great earthquake filling part of the seismic gap west of Katmandu may have been increased to $14 \%$ in the next 30 years.

A slow motion crash between the Indian and Eurasian plates is absorbed at a 18-22 $\mathrm{mm} / \mathrm{yr}$ rate (l) by great earthquakes that raise the Himalayas (FigSB. 1). On the $25^{\text {th }}$ of April, 2015, a $M=7.8$ earthquake ruptured the low-angle $\left(10^{\circ}\right)$ fault contact between the two plates, leading to 7,696 confirmed fatalities, 16,727 people injured, and more than a million families affected (2). Eight UNESCO World Heritage sites were damaged or destroyed. The 2015 shock struck on the eastern edge of a wide gap between historic earthquakes (3) along the Himalayan front (FigSB. 1). Potentially compounding this catastrophe is the possibility of subsequent, lethal triggered earthquakes beneath highly populated basins in the central Himalaya akin to recent tragedies in Turkey (4), China (5), and New Zealand (6). Large triggered earthquake rates are highest immediately after mainshocks, decay exponentially with time, and can persist for years (7). Here we calculate the expected redistribution of stress in the Himalayan crust and develop 


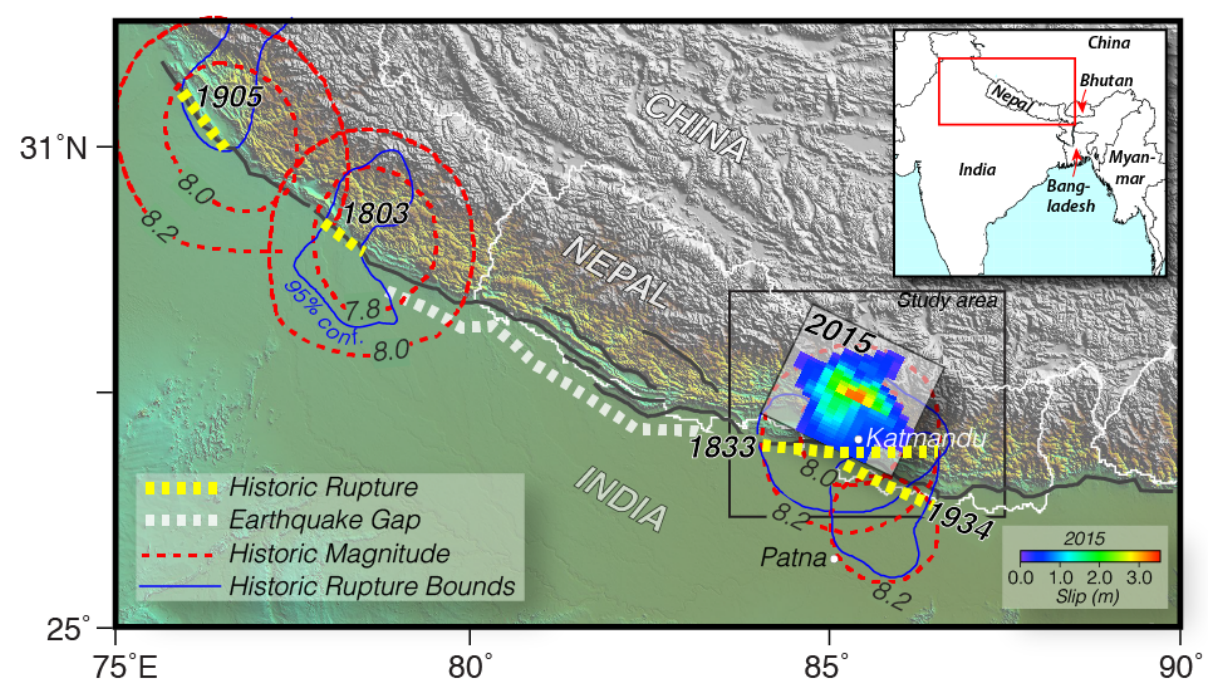


activity, and thus are vulnerable in frontier regions. Physical models depend on our ability to accurately simulate a mainshock rupture and its transfer of stress onto crustal faults. Usually these forecasts rely on Coulomb failure stress changes calculated on hypothetical, optimally oriented faults that align with an estimated regional stress (12) wherein faults may be brought closer to, or further from failure. Constitutive fault parameters are also required (13).

A persistent problem with physical models is that triggered earthquakes happen in areas of calculated stress reduction (known as stress shadows), where theoretically they should be suppressed. We thus develop a new approach that considers the total (preseismic and coseismic) stress field, rather than just the coseismic changes. Solutions for most favorable fault rake and dip are found from the principal axes of the full stress tensor (14). In this mode there are no expected regions of earthquake suppression because there is always a possible fault orientation that is favorable for failure. Certain classes of earthquake mechanism may be suppressed, but others are encouraged (15).

For example, traditional stress change calculations resolved on faults parallel to the mainshock and onto optimal faults cannot fully explain the first 5 days of triggered earthquakes. In both cases significant numbers $(72 \%$ and $48 \%$ respectively) of events occur where stress reductions are calculated (FigSB 2a-b). The total stress field calculations yield a better match; only $12 \%$ of triggered events occurred where the total stress is less than preseismic levels (FigSB. 2c). All stress change methods show the Katmandu prefecture under a coseismic stress increase (FigSB. 2). At the southwest edge of the Katmandu basin, the Thankot 
fault $\left(M_{\max } \sim 6.6\right)(16)$ is calculated to have increased by an average $0.15 \mathrm{MPa}$.

Further to the southwest, calculations show that the Kulekhani fault $\left(M_{\max } \sim 6.9\right)$

(16) stress was increased by $0.32 \mathrm{MPa}$. Stress on the Kalphu-Khola fault
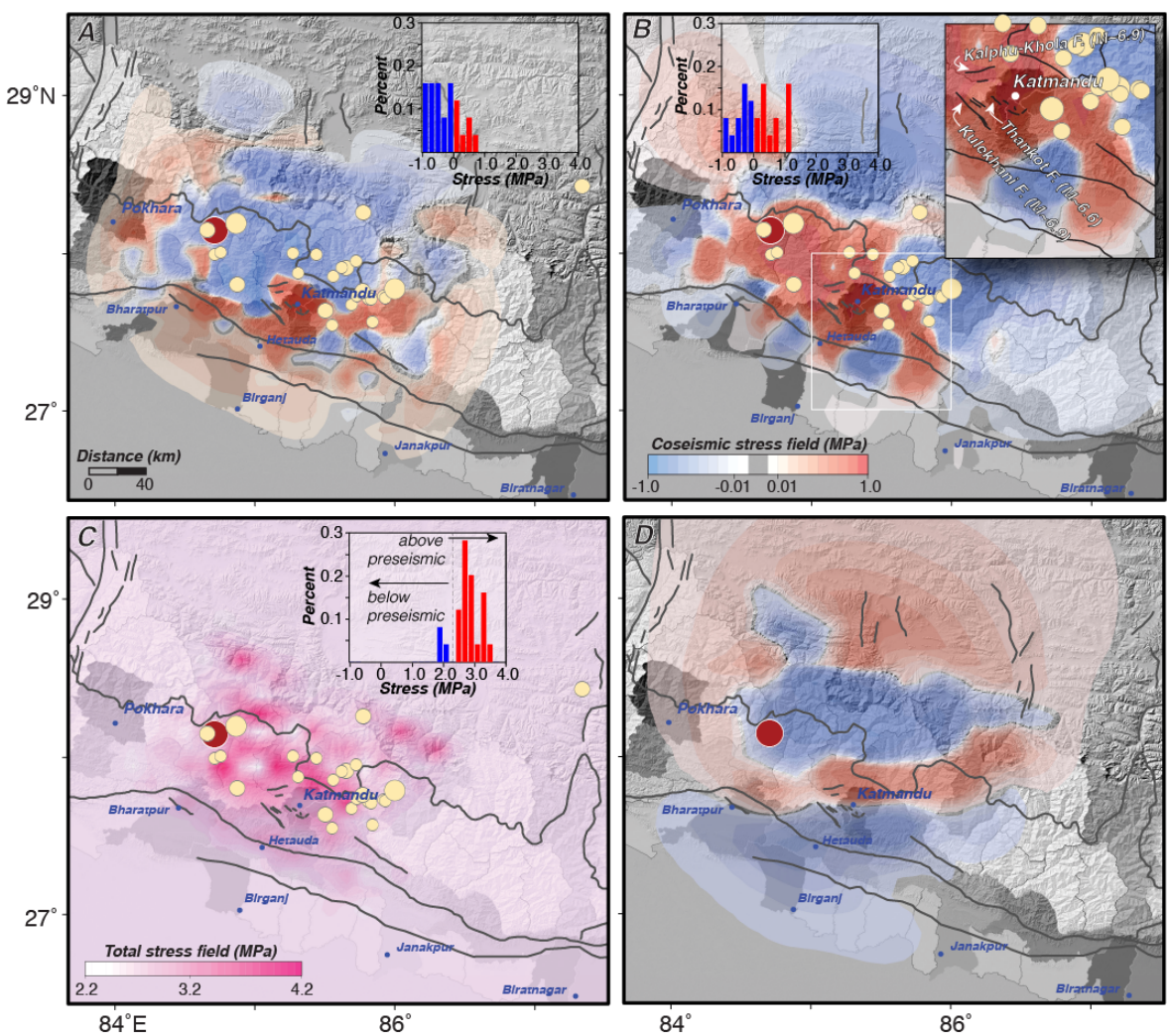

FigSB. 2. Calculated Coulomb stress change distribution from different methods. Triggered earthquakes above the magnitude completeness level of $M \geq 4.7$ are shown as dots, and the mainshock as a red dot. Relative population density by prefecture in Nepal is shown, with densest areas shaded more darkly. Histograms show the number of triggered events in stress-increased and stressdecreased areas. Major faults are shown as black lines. (A) Stress changes are resolved on planes parallel to the mainshock rupture at $10 \mathrm{~km}$ depth. (B) Stress changes are resolved on faults optimally orientated to a horizontal greatest stress 
88

89

90

91

92

93

94

95

96

97

98

99

100

101

102

103

104

105

106

107

108

109

110

111

112

113 direction of $\mathrm{N} 19^{\circ} \mathrm{W}(21)$ at $10 \mathrm{~km}$ depth. A close-up of the Katmandu basin and local faults with maximum magnitude assignments (16) is shown. (C) Total stress (pre-seismic and coseismic change) resolved at $10 \mathrm{~km}$ depth on planes most favorable to resultant principal stress directions and magnitudes. (D) Stress changes resolved on the decollement fault that extends north beneath the Himalayas.

increase on the deep decollement beneath the Himalayas (FigSB 2d), and a 6.5 bar increase on the main boundary thrust immediately west of the 2015 mainshock rupture. As destructive as the 2015 earthquake was, interpretation of paleoseismological (9) and historical shaking intensity (3) observations shows that earthquakes well above $M=8$ occur routinely along the Himalayan front (17) (FigSB. 1).

An operational earthquake forecast involves different time horizons depending on the application, from emergency response (days), restoration $(<1$ year), reconstruction ( $\sim 1-3$ years $)$ and mitigation $(\sim 3+$ years $)$. Here we present forecasts from pure empirical/statistical (11), standard physical (13), and new total stress field methods (14) to compare effects of method on result. Durations cover short (5 days), intermediate (1 month), and long term (5 years).

Statistical models (11) perform especially well with comprehensive earthquake networks capable of recording all shocks to $M=2$ levels. However in frontier regions where these smaller magnitude events go unreported (18), these models significantly underforecast (FigSB. 3a). The two 5-day forecasts we produce based on standard physics (FigSB. 3b-c) also underforecast the early triggered earthquake rates and are spatially limited, failing to capture the breadth of the complete triggered earthquake region. The total-stress forecast predicts 

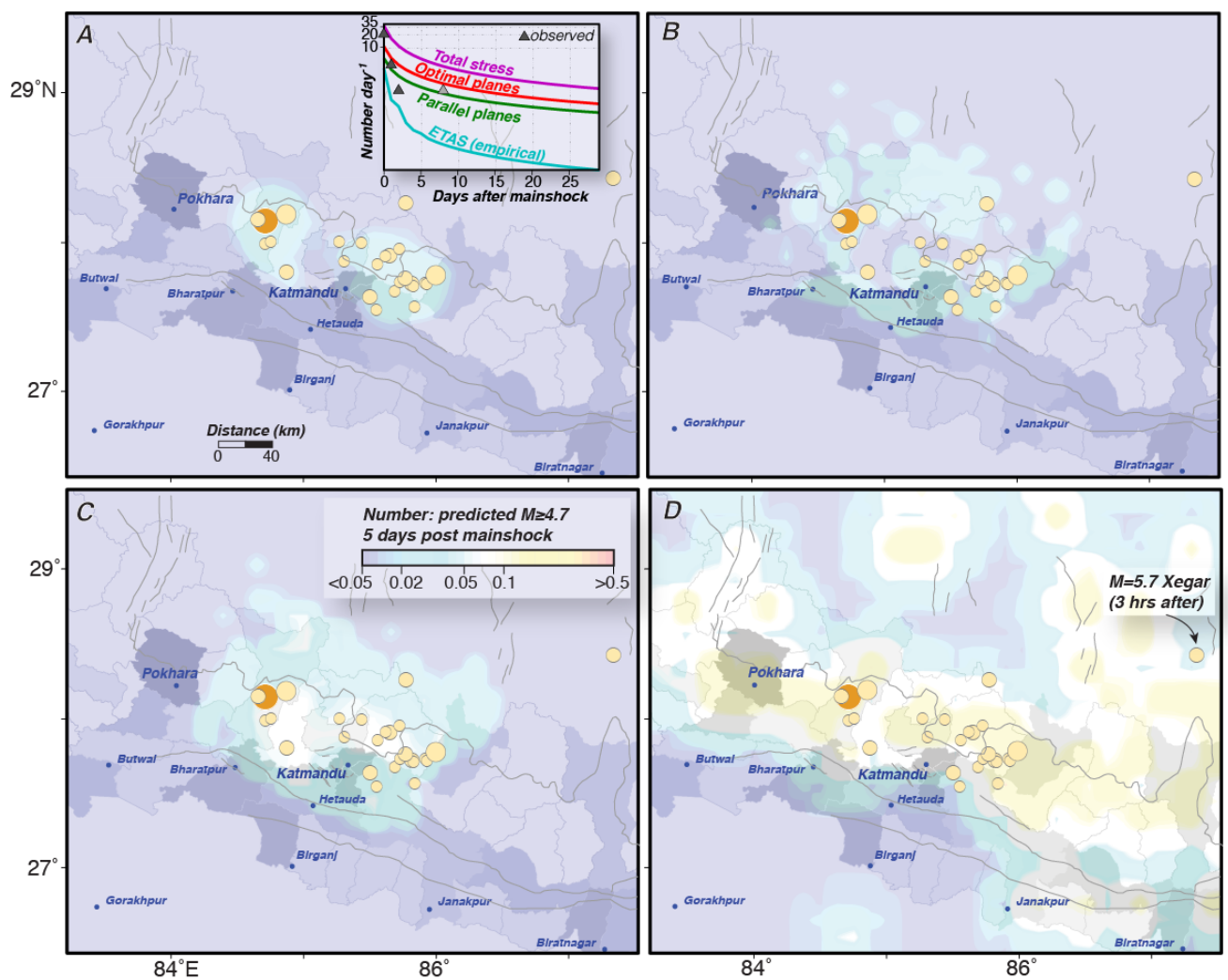

FigSB. 3. Five-day forecast comparisons. Contours show expected numbers of $M \geq 4.7$ events, and the actual distribution of triggered earthquakes is plotted. Relative population density is shown with highest areas darker. (A) The statistical forecast is spatially limited because it depends on the empirical distribution of triggered earthquakes. The inset shows the 30-day forecast rate; dark triangles represent events used to tune the statistical forecast, and the lighter triangle shows a subsequent rate. (B) A forecast based on stress changes resolved on planes parallel to the mainshock rupture is improved relative to the statistical method, but still underreports the first days of seismicity. Forecasts based on (C) optimal fault orientations and (D) the complete stress tensor bracket observed $M \geq 4.7$ rates, with the total stress method forecasting a much wider geographic 

mainshock.

We calculate $M \geq 4.7$ earthquake probability for the coming 5 years using our preferred total stress method, and 30-year time dependent probability (19) on the stress-increased areas of the main boundary thrust west of the 25 April 2015 $M=7.8$ mainshock that has not ruptured since at least AD1505 (FigSB. 4) (9). Results include up to a $14 \%$ chance (increased from $8 \%$ ) of a great earthquake west of Katmandu, and the prospective 5-year earthquake probability map shows a swath parallel to the Himalayan front that is expected ( $\geq 50 \%$ chance) to experience moderate to strong earthquakes. Aggregated probability from mapped faults (16) in the Katmandu Basin shows a 90\% chance of at least one more $M \geq 4.7$ shock in the next 5 years. Validation of the 5-year forecast through tracking future seismicity will assess the predictive skills of our forecast.

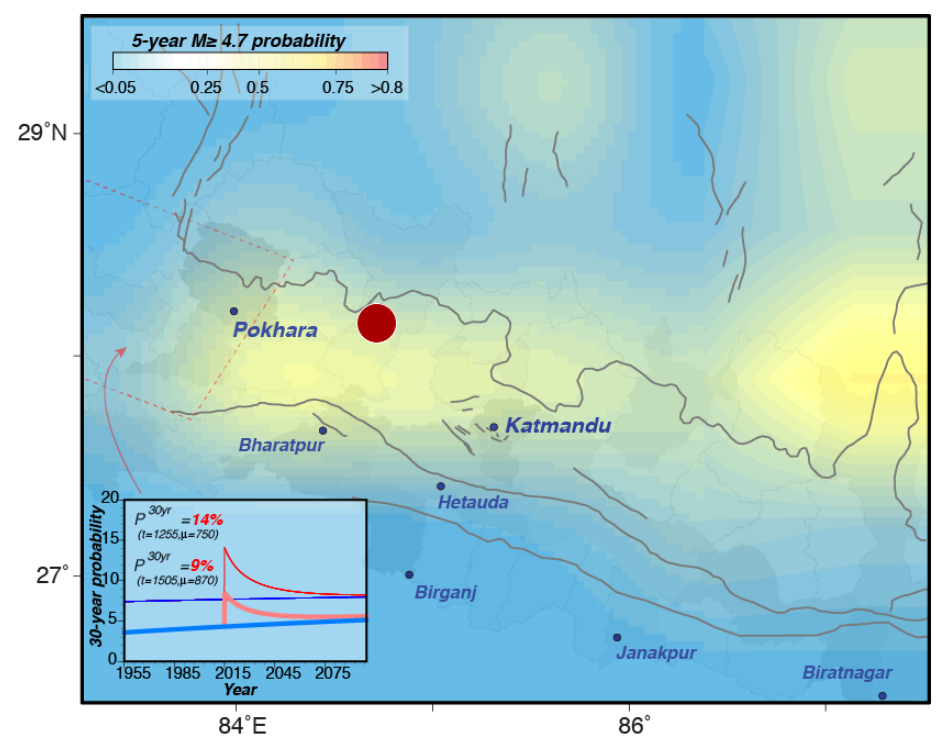


FigSB. 4. Five year probabilistic forecast for the Katmandu region and affected areas along the Himalayan front. Probability of $M \geq 4.7$ earthquakes during the next 5 years is contoured. Generally, a band of heightened probability tracks along the Himalayan front that is of particular concern west of the 25 April $2015 M=7.8$ mainshock, given that a great earthquake has not occurred there in hundreds of years. The lower inset shows time dependent probability (19) vs. time specific to stress-increased parts of the main boundary thrust range from 9$14 \%$ (increased from $4-8 \%$ ) in the next 30 years (recurrence parameters adopted from (9)).

\section{REFERENCES AND NOTES}

1. Ader, T., et al. (2012), Convergence rate across the Nepal Himalaya and interseismic coupling on the Main Himalayan Thrust: Implications for seismic hazard, J. Geophys. Res., 117, B04403, doi:10.1029/2011JB009071.

2. Figures from Nepal Red Cross Society.

3. We use the method of W. H. Bakun and C. M. Wentworth, Bull. Seis. Soc. Am. 87, 1502 (1997) to calculate historic earthquake locations from historical intensity observations compiled by S. Martin and W. Szeliga, Bull. Seis. Soc. Am. 100, 562 (2010).

4. Parsons, T., S. Toda, R. S. Stein, A. Barka, and J. H. Dieterich, Science 288, 661, (2000).

5. Parsons, T., C. Ji, and E. Kirby, Nature 454, 509 (2008), Parsons, T., and M. Segou, Seis. Res. Lett. 85, 44 (2014).

6. Stramondo, S., C. Kyriakopoulos, C. Bignami, M. Chini, D. Melini, M. Moro, M. Picchiani, M. Saroli, and E. Boschi, Scientific Reports 1, Article number 98. (2011).

7. Omori, F., On aftershocks, Report of Imperial Earthquake Investigation Committee, 2, 103-109, 1894. Utsu, T., 1961, Statistical study on the occurrence of aftershocks, Geophys. Mag., 30, 521-605. Parsons, T. (2002), Global Omori law decay of triggered earthquakes: Large aftershocks outside the classical aftershock zone, Journal of Geophysical Research, 107, 2199, doi:10.1029/2001JB000646.

8. http://earthquake.usgs.gov/earthquakes/eventpage/us20002926\#scientific_finitefault

9. Rajendran, C. P., B. John, and K. Rajendran (2015), Medieval pulse of great earthquakes in the central Himalaya: Viewing past activities on the frontal thrust, J. Geophys. Res., 120. Bollinger, L., S. N. Sapkota, P. Tapponnier, Y. Klinger, M. Rizza, J. Van der Woerd, D. R. Tiwari, R. Pandey, A. Bitri, and S. Bes de Berc (2014), Estimating the return times of great Himalayan earthquakes in eastern Nepal: Evidence from the Patu and Bardibas strand of the MainFrontal Thrust, J. Geophys. Res. Solid Earth, 119, 7123-7163. Primary surface ruptures of the great Himalayan earthquakes in 1934 and 1255, S. N. Sapkota, L. Bollinger, Y. Klinger, P. Tapponnier, Y. Gaudemer and D. Tiwari (2013), Nature Geoscience, 6, 71-76.

10. T. H. Jordan, W. Marzocchi, A. J. Michael, and M. C. Gerstenberger (2014), Operational earthquake forecasting can enhance earthquake preparedness, Seis. Res. Lett., 85, 955959.

11. We use the Epidemic Type Aftershock (ETAS) model (20), where the space-time seismicity rate $\lambda(x, y, t)$ is given by $\lambda(x, y, t)=\mu(x, y)+\sum_{i: t_{i<t}} \frac{\kappa e^{\alpha\left(M_{i}-M_{t h}\right)}}{\left(t-t_{i}+c\right)^{p}} f_{i}\left(x-x_{i}, y-y_{i} ; M_{i}\right)$, 
where $f(x, y ; M)=\frac{q-1}{\pi D(M)}\left(1+\frac{x^{2}+y^{2}}{D(M)}\right)^{-q}$, and $D(M)=d e^{\gamma\left(M-M_{\min }\right)}$. Parameter $\mu$ is the

191

192

193

194

195

196

197

198

199

200

201

202

203

204

205

206

207

208

209

210

211

212

213

214

215

216

217

218

219

220

221

222

223

224

225

226

227

228

229

background rate, $\kappa, c$, and $p$ are Omori-law values ( 7 ) governing the decay rate of aftershocks, $a$ estimates the magnitude efficiency of an earthquake in generating its offspring; $d, \gamma$ and $q$ are spatial fitting parameters. The Nepal catalog is complete to $M \geq 4.7$, but we allowed the ETAS model to use all available earthquakes to achieve optimum performance.

12. Stein, R. S., 1999, The role of stress transfer in earthquake Occurrence, Nature, 402, 605-609.

13. Coulomb failure stress $\left(\Delta C F \equiv \Delta\left|\bar{\tau}_{f}\right|+\mu^{\prime}\left(\Delta \sigma_{n}\right), \mu^{\prime}=\mu\left(1-B_{k}\right)\right)$ where $\Delta \bar{\tau}_{f}$ is the change in shear stress on the receiver fault, $\mathrm{m}$ is the coefficient of friction, $\Delta \sigma_{n}$ is the change in normal stress, and $B_{k}$ is Skempton's coefficient (accounts for pore fluid pressure). Stress values are found by slipping an elastic dislocation representation of the mainshock slip model (8). Friction coefficient is taken to be 0.4. A $10 \mathrm{MPa}$ deviatoric tectonic stress with compression oriented $\mathrm{N} 19^{\circ} \mathrm{W}(21)$ is used to find optimally oriented receiver fault planes. The same magnitude and direction is used for the total stress method. Additionally, we calculate stress change on planes parallel to, and on the mainshock fault to find likely future rupture areas on the main boundary fault and other possibly hidden faults of like orientation (22). Following the rate-and-state friction framework (23) the pre-mainshock earthquake activity $R$, as , $R=\frac{r}{\gamma \dot{\tau}}$, where $\gamma_{n}=\gamma_{n-1} \exp \left(\frac{-\Delta C F}{a \sigma}\right)$, is suppressed or enhanced by static stress changes. The decay rate of this effect is inversely correlated with the shear stressing rate $(\dot{\tau})$. Daily forecast parameters are: $a \sigma=0.5(24)$ and $\dot{\tau}=0.00239 \mathrm{MPa} / \mathrm{yr}$, based on regional thrust fault slip rates of $\sim 10 \mathrm{~mm} / \mathrm{yr}(1)$.

14. The total stress tensor is the sum of the presesimic stress and stress change tensors $\sigma_{x, y, z}^{T}=\sigma_{x, y, z}^{P R E}+\Delta \sigma_{x, y, z}$. The strike angle between principal stress axes and the favored fault plane $\beta$ is from $\tan 2 \beta=1 / \mu$ (25). A grid search is performed in $5^{\circ}$ steps over dip and rake to maximize Coulomb failure for all possible mechanism classes (reverse, normal, and transform) (26).

15. Mallman, E. P., and T. Parsons (2008), A Global Search for Stress Shadows, J. Geophys. Res., v. 113, doi:10.1029/2007JB005336.

16. National Society for Earthquake Technology-Nepal (NSET), Shelter response strategy and plan for earthquake disasters for Kathmandu Valley, Nepal, 60 pp. (2010).

17. R. Bilham,Vi. K. Gaur, P. Molnar, Himalayan seismic hazard, Science, 293, 1442-1444.

18. Kagan, Y. Y. (2003), Accuracy of modern global earthquake catalogs, Phys. Earth Planet. Int., 135, 173-209.

19. Time-dependent seismicity rate $R(t)$ after a stress perturbation is $R(t)=\frac{r}{\left[\exp \left(\frac{-\Delta C F F}{a \sigma}\right)-1\right] \exp \left[\frac{-t}{t_{a}}\right]+1}(23)$ where $r$ is the steady-state seismicity rate,

$\triangle C F F$ is the stress step, aftershock duration $t_{a}$ is assumed to be 25 years, and $a \sigma=0.5$ (24). $R(t)$ is related to earthquake probability over the interval $\Delta t$ as

$P(t, \Delta t)=1-\exp \left[-\int_{t}^{t+\Delta t} R(t) d t\right]=1-\exp (-N(t))(27)$ where 
$N(t)=r_{p}\left\{\Delta t+t_{a} \ln \left[\frac{1+\left[\exp \left(\frac{-\Delta C F F}{a \sigma}\right)-1\right] \exp \left[\frac{-\Delta t}{t_{a}}\right]}{\exp \left(\frac{-\Delta C F F}{a \sigma}\right)}\right]\right\}$, and $r_{p}=\left(\frac{-1}{\Delta t}\right) \ln \left(1-P_{c}\right)$ where Pc is a

conditional probability. We calculate time dependent probability using a Brownian Passage Time distribution with aperiodicity $=0.5$ and bracket the calculations with mean recurrence intervals ranging from $750-870$ years and last earthquake times either 1255 or 1505 (9).

20. Ogata Y., 1988, Statistical models for earthquake occurrences and residual analysis for point processes, J. Amer. Statist. Assoc., 83, 9-27. Ogata, Y., (1998). Space-time pointprocess models for earthquake occurrences, Ann. Inst. Stat. Math., 50, 379-402.

21. F. Jouanne, J. L. Mugnier, J. F. Gamond, P. Le Fort, M. R. Pandey, L. Bollinger, M. Flouzat and J. P. Avouac, Current shortening across the Himalayas of Nepal, Geophys. J. Int. (2004) 157, 1-14.

22. C. Wobus, A. Heimsath, K. Whipple, and K. Hodges, Active out-of-sequence thrust faulting in the central Nepalese Himalaya, Nature, 434, 1008-1011.

23. Dieterich, J. (1994), A constitutive law for rate of earthquake production and its application to earthquake clustering, J. Geophys. Res., 99, 2601-2618.

24. S. Toda, B. Enescu, Rate/state Coulomb stress transfer model for the CSEP Japan seismicity forecast, Earth Planets Space, Vol. 63 (No. 3), pp. 171-185, 2011.

25. Jaeger, J. C., and N. G. W. Cook, Fundamentals of Rock Mechanics, Chapman and Hall, London, England, 1976.

26. Aki, K., and P. G. Richards, 1980, Quantitative Seismology, 932 pp., W.H. Freeman \& Co., New York.

27. Dieterich, J. H., and B. Kilgore (1996), Implications of fault constitutive properties for earthquake prediction, Proc. Nat. Acad. of Sci. USA, 93, 3787-3794. 
From: science_editors@aaas.org

Subject: Successful Submission of a Manuscript to Science

Date: May 9, 2015 at 4:18 PM

Manuscript Title: Impending earthquakes beneath Katmandu and the Himalayan front after the 25 April $2015 \mathrm{M}=7.8 \mathrm{Nepal}$ mainshock

Author: Parsons

Manuscript Number: aac5455

Dear Dr. Parsons:

Thank you for your submission to Science. We have successfully received your Report.

You can see the status of your manuscript at any time by logging into your account at the Science Journals Submission and Information Portal at https://cts.sciencemag.org. Your manuscript number is noted above. Your manuscript is now undergoing an initial screening to determine whether it will be sent for in-depth review. If the manuscript is sent to review, its status will change to "To Review".

We encourage you to login and link your account to your ORCID ID, an identifier that facilitates correct attribution of your publications. To learn more about ORCID or to obtain an ORCID ID, visit their site at: http://orcid.org.

Sincerely,

The Editors

Science 